\title{
Oxidative DNA damage and repair in the radioresistant archaeon Thermococcus gammatolerans
}

\author{
Barbier Ewa ${ }^{1,2}$, Lagorce Arnaud ${ }^{3,4}$, Hachemi Amine ${ }^{3}$, Dutertre Murielle ${ }^{3}$, Gorlas Aurore ${ }^{1,2}$, \\ Morand Lucie ${ }^{1,2}$, Saint-Pierre Christine ${ }_{1,2}^{1,2}$, Ravanat Jean-Luc ${ }^{1,2}$, Douki Thierry ${ }_{1,2}^{1,2}$, Armengaud Jean ${ }^{5}$, \\ Gasparutto Didier ${ }^{1,2}$, Confalonieri Fabrice ${ }^{3}$, Breton Jean ${ }^{1,2}$
}

${ }^{1}$ Univ. Grenoble Alpes, INAC, LCIB, F-38000 Grenoble, France

${ }^{2}$ CEA, INAC, SyMMES, F-38000 Grenoble, France

${ }^{3}$ Univ. Paris-Sud, Institute for Integrative Biology of the Cell (I2BC), Université Paris Saclay, CEA, CNRS, Orsay, France

${ }^{4}$ Univ. Perpignan, IHPE - UMR 5244 CNRS/IFREMER/Univ. Montpellier, Montpellier, F- 34095, France

${ }^{5}$ CEA, DSV-Li2D, Laboratory "Innovative technologies for Detection and Diagnostics", BP 17171, Bagnols-sur-Cèze, F-30207, France

*Corresponding author : Jean Breton, email address : jean.breton@cea.fr

\begin{abstract}
:
The hyperthermophilic archaeon Thermococcus gammatolerans can resist huge doses of $\mathrm{y}$-irradiation up to $5.0 \mathrm{kGy}$ - without loss of viability. The potential to withstand such harsh conditions is probably due to complementary passive and active mechanisms, including repair of damaged chromosomes. In this work, we documented the formation and repair of oxidative DNA lesions in $T$. gammatolerans. The basal level of the oxidized nucleoside, 8-oxo-2'-deoxyguanosine (8-oxo-dGuo), was established at 9.2 $(+/-0.9)$ 8-oxo-dGuo per 106 nucleosides, a higher level than those usually measured in eukaryotic cells or bacteria. A significant increase in oxidative damage, i.e. up to 24.2 (+/- 8.0) 8-oxo-dGuo/106 nucleosides, was measured for $T$.gammatolerans exposed to a $5.0 \mathrm{kGy}$ dose of $\mathrm{Y}$-rays. Surprisingly, the yield of radiation-induced modifications was lower than those previously observed for human cells exposed to doses corresponding to a few grays. One hour after irradiation, 8-oxo-dGuo levels were significantly reduced, indicating an efficient repair. Two putative base excision repair (BER) enzymes, TGAM_1277 and TGAM_1653, were demonstrated both by proteomics and transcriptomics to be present in the cells without exposure to ionizing radiation. Their transcripts were moderately upregulated after gamma irradiation. After heterologous production and purification of these enzymes, biochemical assays based on electrophoresis and MALDI-TOF (Matrix-Assisted Laser Desorption lonization - Time Of Flight) mass spectrometry indicated that both have a $\beta$-elimination cleavage activity. TGAM_1653 repairs 8-oxo-dGuo whereas TGAM_1277 is also able to remove lesions affecting pyrimidines (1-[2deoxy- $\beta$-D-erythro-pentofuranosyl]-5-hydroxyhydantoin (5-OH-dHyd) and 1-[2-deoxy- $\beta$-D-erythropentofuranosyl]-5-hydroxy-5-methylhydantoin (5-OH-5-Me-dHyd)). This work showed that, in normal growth conditions or in the presence of a strong oxidative stress, T. gammatolerans has the potential to rapidly reduce the extent of DNA oxidation, with at least these two BER enzymes as bodyguards with distinct substrate ranges.
\end{abstract}




\section{Graphical abstract}

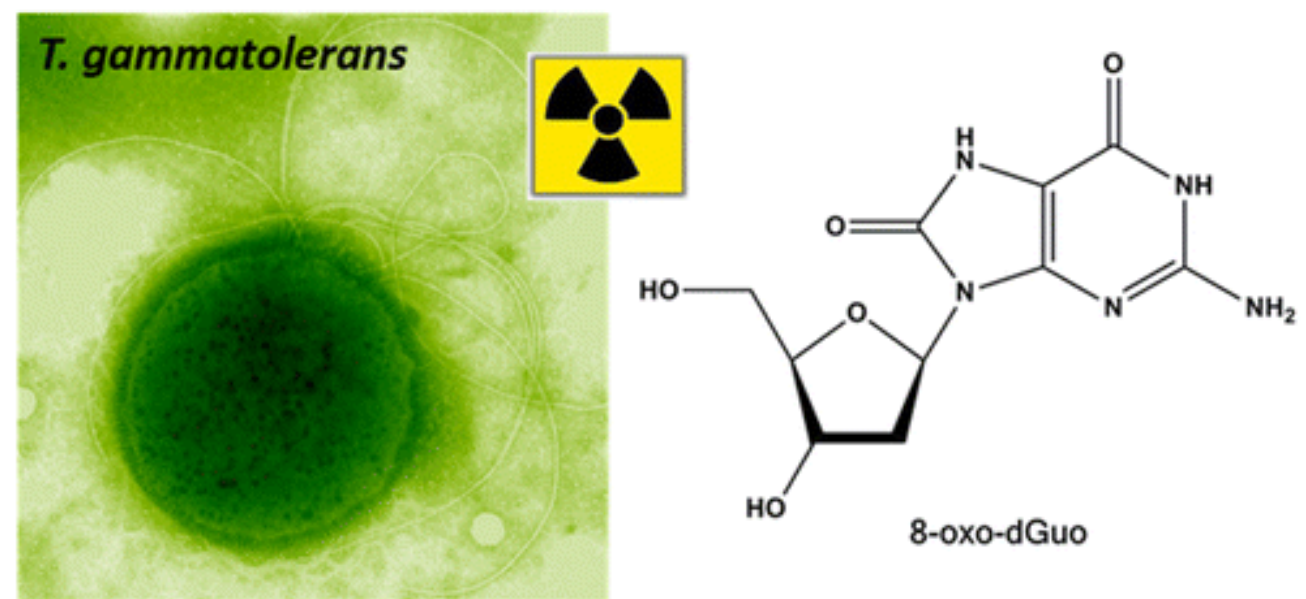

Keywords : Radioresistance; archaeon; oxidative DNA damage; base excision repair; glycosylase 


\section{INTRODUCTION}

Extremophile microorganisms have developed a wide range of mechanisms to survive in harsh environmental conditions. Thermococcus gammatolerans, a hyperthermophilic prokaryote described as the most radioresistant archaeon identified to date, was isolated from samples obtained in a hydrothermal vent located in the Gulf of California. ${ }^{1}$ This obligatory anaerobic heterotrophic organism has a genome of 2.04 megabases $(\mathrm{Mb})$, shows an optimal growth temperature of $88^{\circ} \mathrm{C}$, and fully withstands a 5.0 kiloGrays (kGy) dose of gamma irradiation without loss of viability. ${ }^{2}$ The molecular and biological mechanisms explaining this remarkable resistance of $T$. gammatolerans have not yet been defined. This microorganism probably combines different and complementary strategies to resist such hostile conditions, as is the case for other radiotolerant organisms. ${ }^{3}$ Ionizing radiation is associated with the production of reactive oxygen species (ROS), passive resistance mechanisms consist of modification of the $\mathrm{Mn} / \mathrm{Fe}$ intracellular ion ratio and the production of "compatible solutes" composed of chemical agents such as polyols, sugars and amino acids allowing the stabilization of macromolecules. ${ }^{4}$ A more active mechanism involves combating oxidative stress using antioxidant enzymes. Finally, another way to resist ionizing radiation is to repair shattered chromosomal DNA as efficiently as possible. Pulsed field gel electrophoresis has allowed time course analysis of the archaeon chromosomal repair after irradiation. Such experiments have indicated that $T$. gammatolerans chromosomes are fully degraded after a $5.0 \mathrm{kGy}$ dose of $\gamma$-rays. DNA strand breaks are fully repaired after $5 \mathrm{~h}$ by cells in stationary phase, while $6 \mathrm{~h}$ are necessary for cells in exponential growth phase. ${ }^{5}$ Proteomic approaches have demonstrated that $T$. gammatolerans produces key factors of the main DNA repair systems such as base excision repair (BER) and Double-Strand Break Repair. ${ }^{2}$ It is worth noting that some of these proteins are present in the absence of stress, 
which may be useful for survival in the harsh conditions that constantly surround these extremophiles, or during drastic environmental changes that are especially unfavorable to life. Despite a growing amount of data regarding radiotolerant organisms, DNA repair mechanisms in Archaea, and particularly in T. gammatolerans, remain poorly understood. Most of the DNA alterations resulting from high doses of radiation have never been analyzed in radioresistant archaea. Among these, 8-oxo-2'-deoxyguanosine (8-oxo-dGuo) is a classic biomarker of oxidative stress. Its chemical structure is presented in Fig. 1. The main mechanism of formation of 8-oxo-dGuo upon exposure to ionizing radiation depends on an indirect effect: the radiolysis of water generates the hydroxyl radical ${ }^{\circ} \mathrm{OH}$ which reacts with $\mathrm{C} 8$ of the guanine. ${ }^{6}$ Mutations (mainly $\mathrm{G} \rightarrow \mathrm{T}$ transversions) can occur in the genome if 8-oxodGuo is not repaired prior to replication. ${ }^{7}$ Sample preparation and measurement of 8-oxodGuo are technically challenging to avoid DNA artifactual oxidation, and as a consequence misleading results can be found in the literature. ${ }^{6}$ DNA lesions $5^{\prime}, 8$-cyclonucleosides (Fig. 1) are radiation-induced, tandem base-sugar alterations usually produced in lower yields than 8oxo-dGuo but with a more severe biological impact resulting from a drastic alteration of the DNA structure. ${ }^{8}$ The formation of these complex DNA lesions is known to be favored at low oxygen concentrations. ${ }^{9}$ The large radiation dose that can be applied to T. gammatolerans cells and their natural anaerobic growth conditions makes the quantitation of 5',8cyclonucleosides highly relevant.

In the present study, we first quantified oxidative DNA damage in T. gammatolerans, both at basal levels and after exposure to high doses of $\gamma$-irradiation, by measuring 8-oxo-dGuo and 5',8-cyclonucleosides by HPLC coupled to tandem mass spectrometry (HPLC-MS/MS). We also documented the molecular mechanisms of two putative BER enzymes identified in the genome: TGAM_1277, initially annotated as a putative type III endonuclease (endoIII), and 
TGAM_1653, a predicted DNA glycosylase, ${ }^{2}$ phylogenetically close to the 8 -oxoguanine glycosylase from Pyrobaculum aerophilum. ${ }^{10}$ Transcriptomics and proteomics were used to assess their presence in $T$. gammatolerans with and without exposure to irradiation. After their heterologous production, TGAM_1277 and TGAM_1653 proteins were assayed for their cleaving activities on different oxidative DNA lesions by electrophoresis and Matrix-Assisted Laser Desorption Ionization - Time Of Flight (MALDI-TOF) mass spectrometry. 


\section{EXPERIMENTAL PROCEDURES}

\section{T. gammatolerans growth conditions}

The T. gammatolerans EJ3 strain was cultivated in serum bottles or in $1 \mathrm{~L}$ Schott bottles, under anaerobic conditions at $85^{\circ} \mathrm{C}$ in complex organic medium (VSM), as described in ${ }^{2}$. Cell culture densities were measured by optical microscopy (Olympus BH-29) using a Thoma counting chamber (Microgravure Precis).

\section{Gamma irradiation and DNA extraction}

\section{Gamma irradiation}

For 8-oxo-dGuo quantification after irradiation, large volumes of exponentially growing cells $\left(600 \mathrm{~mL}\right.$ in $1 \mathrm{~L}$ Schott bottles, $7 \times 10^{7}$ cells $\left./ \mathrm{mL}\right)$ were filtered (MicraCloth Calbiochem, La Jolla, CA, USA) to remove sulfur compounds from the VSM-S ${ }^{\circ}$ medium. In anaerobic conditions, cells were concentrated X10 in Hungate tubes for $\gamma$-irradiation. Cells were then exposed on ice to a dose of $2.5 \mathrm{kGy}$ or $5.0 \mathrm{kGy}(100 \% \text { survival })^{5}$ using a ${ }^{137} \mathrm{Cs} \gamma$-ray source (40 Gy/min, IBL637 CisBio International, Institut Curie, Orsay, France). As a control, the same number of nonirradiated cells was kept on ice during irradiation. Irradiated and nonirradiated cells were either collected immediately or incubated for $60 \mathrm{~min}$ at $85^{\circ} \mathrm{C}$ for recovery in fresh VSM-S ${ }^{\circ}$ medium on a reciprocal shaker before centrifugation (4000 g, 20 min at $4{ }^{\circ} \mathrm{C}$ ). Cells were immediately frozen and stored at $-80^{\circ} \mathrm{C}$ until further processing. Each culture was performed in independent duplicates.

For gene expression assays, $600 \mathrm{~mL}$ exponentially growing cells were filtered (MicraCloth Calbiochem, La Jolla, CA, USA) to remove sulfur compounds from the VSM-S ${ }^{\circ}$ medium and 
concentrated ten-fold by centrifugation. Cells were exposed on ice to a dose of $2.5 \mathrm{kGy}$ or 5.0 kGy using a ${ }^{137} \mathrm{Cs} \gamma$-ray source (19 Gy/min, GSR D1 GSM, Institut Curie, Orsay, France). As a control, the same number of nonirradiated cells was kept on ice during irradiation. Irradiated and nonirradiated cells were either collected immediately or incubated for 60 or $120 \mathrm{~min}$ at $85^{\circ} \mathrm{C}$ for recovery in fresh VSM-S ${ }^{\circ}$ medium on a reciprocal shaker before centrifugation $\left(4000 \mathrm{~g}, 20 \mathrm{~min}\right.$ at $\left.4^{\circ} \mathrm{C}\right)$. Cells were immediately frozen and stored at $-80^{\circ} \mathrm{C}$ until further processing. Each culture was repeated twice.

\section{DNA extraction and digestion}

T. gammatolerans cells (10 mg) were supplemented with $300 \mu \mathrm{L}$ lysis buffer containing $100 \mathrm{mM}$ Tris- $\mathrm{HCl} \mathrm{pH} 8.3,50 \mathrm{mM}$ EDTA, $100 \mathrm{mM} \mathrm{NaCl}$, and $0.15 \mathrm{mM}$ deferoxamine. Thirty $\mu \mathrm{L} 10 \% \operatorname{SDS}(\mathrm{v} / \mathrm{v})$ and $30 \mu \mathrm{L} 10 \%$ sarkosyl (v/v) were then added to the cell suspension. The samples were incubated with $150 \mu \mathrm{g}$ RNAse A (Sigma) and 3.5 U RNAse T1 (Sigma) for $15 \mathrm{~min}$ at $50^{\circ} \mathrm{C}$. Six hundred $\mu \mathrm{g}$ protease (Qiagen) were added and the incubation was pursued for $1.5 \mathrm{~h}$ at $37^{\circ} \mathrm{C}$. DNA was precipitated with $600 \mu \mathrm{L} 20 \mathrm{mM}$ EDTA-Na, $7.6 \mathrm{M}$

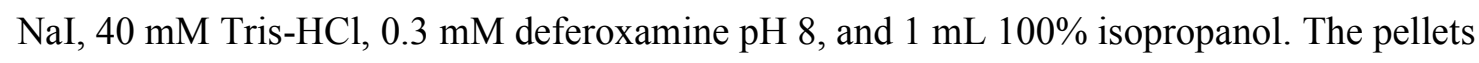
were washed with $40 \%$ isopropanol (v/v) and subsequently with $70 \%$ ethanol (v/v), and finally suspended in $50 \mu \mathrm{L} 0.1 \mathrm{mM}$ deferoxamine.

The DNA digestion was performed in two steps. First, $0.025 \mathrm{U}$ phosphodiesterase II, $2.5 \mathrm{U}$ DNAse II, 0.5 U nuclease P1 (Sigma) and $2.5 \mu \mathrm{L}$ buffer (200 mM succinic acid, $100 \mathrm{mM}$ $\mathrm{CaCl}_{2}, \mathrm{pH}$ 6) were added and the samples were incubated for $2 \mathrm{~h}$ at $37^{\circ} \mathrm{C}$. Then, $6 \mu \mathrm{L}$ $500 \mathrm{mM}$ Tris-HCl, $1 \mathrm{mM}$ EDTA pH 8, $0.015 \mathrm{U}$ phosphodiesterase I (Worthington) and $2 \mathrm{U}$ alkaline phosphatase (Sigma) were added and the samples were incubated for $2 \mathrm{~h}$ at $37^{\circ} \mathrm{C}$. The reaction was stopped by adding $3.5 \mu \mathrm{L} 0.1 \mathrm{~N} \mathrm{HCl}$. For the cyclonucleoside detection, the first step of the digestion was repeated before adding $\mathrm{HCl}$, as optimized previously. ${ }^{9}$ 


\title{
HPLC-MS/MS quantification of 8-oxo-dGuo and 5',8-cyclonucleosides
}

\author{
8-oxo-dGuo
}

Digested DNA samples were resolved on an Uptisphere 2x150 mm octadecylsilyl silica gel column (Interchim) operated with an Agilent series 1100 HPLC system. The mobile phase was a gradient of methanol in $2 \mathrm{mM}$ aqueous ammonium formate ( 2 to $10 \%(\mathrm{v} / \mathrm{v})$ in $25 \mathrm{~min}$ and 10 to $25 \%(\mathrm{v} / \mathrm{v})$ in the following $10 \mathrm{~min})$. Undamaged nucleosides were monitored with a UV detector set at $260 \mathrm{~nm}$ while 8-oxo-dGuo was measured in positive mode with an API 3000 triple quadrupolar mass spectrometer (PerkinElmer/SCIEX) equipped with ElectroSpray Ionisation (ESI). The system was operated in the multiple reaction monitoring mode using a specific transition $(\mathrm{m} / \mathrm{z} 284 \rightarrow 168)$. DNA damage rates measured in different experimental conditions were compared using the Mann-Whitney test $(p<0.05)$. For each condition, five measurements were performed: two technical replicates for the first biological sample and three technical replicates for the second biological sample.

\section{5',8-cyclonucleosides}

Four lesions were measured simultaneously: $5^{\prime} R$ and 5' $S$ diastereomers of 5',8-cyclo-2'deoxyadenosine (5',8-cyclodAdo) and 5',8-cyclo-2'-deoxyguanosine (5',8-cyclodGuo). Digested DNA samples were resolved on an Uptispher 2x150 mm column of silica octadecylsilyle (Interchim) operated with an Accela HPLC (Thermo Corporation). Nucleosides were resolved by a linear gradient of acetonitrile ( 0 to $15 \%(\mathrm{v} / \mathrm{v})$ gradient in 30 min) in ammonium formate. Undamaged nucleosides were detected at $260 \mathrm{~nm}$ with a UV detector while cyclonucleosides were specifically monitored as previously described ${ }^{9}$ with a TSQ Quantum Ultra mass detector equipped with ESI. 


\section{Transcriptomic and proteomic analysis of TGAM_1277 and TGAM_1653}

For expression profiling by real-time RT-PCR (Reverse Transcription PCR), total RNAs were extracted with TriReagent solution (Sigma) and genomic DNA was digested by Turbo DNAse (Ambion) according to the manufacturer's instructions. The absence of genomic DNA in RNA samples was checked by PCR using 16S rRNA primers (Table S1) and $2 \mu \mathrm{g}$ total RNA as template. Reverse transcription was performed in a total volume of $20 \mu \mathrm{L}$ in the presence of $5 \mu \mathrm{g}$ total RNA, 2 pmol gene-specific reverse primers (Table S1), $0.5 \mathrm{mM}$ each dNTP and 200 units SuperScriptII (Invitrogen, Carlsbad, CA). After a 30 min incubation at $42^{\circ} \mathrm{C}, 200$ units SuperScriptII were added and the samples were incubated at $42^{\circ} \mathrm{C}$ for $30 \mathrm{~min}$. The hydrolysis of the RNA was performed in the presence of $11 \mu \mathrm{L} 1 \mathrm{~N} \mathrm{NaOH}$ for 10 min at $70^{\circ} \mathrm{C}$ and the solution was neutralized with $11 \mu \mathrm{L} 1 \mathrm{~N} \mathrm{HCl}$. cDNAs were desalted with MicroconG30 (Millipore), dried under vacuum and resuspended in $10 \mu \mathrm{L}$ water. cDNA templates were diluted 1/100 with water for expression measurements. Standard conditions were used with LightCycler FastStart DNA MasterPLUS SYBR green I (Roche), i.e. DNA denaturation at $95^{\circ} \mathrm{C}$ for $10 \mathrm{~min}$ followed by 40 cycles of $95^{\circ} \mathrm{C}$ for $10 \mathrm{~s}, 60^{\circ} \mathrm{C}$ for $10 \mathrm{~s}$ and $72^{\circ} \mathrm{C}$ for $15 \mathrm{~s}$, using the LightCycler System (Roche Diagnostics). Gene expression was calculated relative to the geometric average expression of four reference genes using the formula $2^{-\Delta \mathrm{Ct}} \cdot{ }^{11,12}$ The reference genes used in this work, namely TGAM_0829, TGAM_01054,TGAM_1165, and TGAM_1926, encode a TATA box-binding protein (tbp), an elongation factor 1-alpha (tuf), a CDP-alcohol phosphatidyltransferase, and a DNA-directed RNA polymerase subunit B (rpoB ),${ }^{13}$ respectively. Expression of these selected reference genes remains particularly stable in T. gammatolerans cells challenged with heavy metal (i.e. cadmium) ${ }^{13}$ or with ionizing radiation, as revealed by genome-wide transcriptomic data (unpublished data). Proteomics information for TGAM_1277 and TGAM_1653 were extracted from data we had previously 
obtained through a shotgun proteomic analysis, now available on the ProteomeXchange Consortium (dataset identifier PXD000402).

\section{Heterologous production and purification of BER enzymes}

Bacterial strains and expression plasmids

E. coli strain DH5 $\alpha$ (Life Technologies) was used in all cloning experiments and for plasmid amplifications. The E. coli Rosetta (DE3) strain (Novagen) was used for protein production. The pET30a(+) plasmid (Novagen) was used for bacterial expression of N-terminal His $6_{6}^{-}$ tagged proteins.

Cloning and expression of TGAM_1277 and TGAM_1653 glycosylase genes TGAM_1277 (230 aa) and TGAM_1653 (263 aa) coding DNA sequences (CDS) were first amplified by PCR with genomic DNA as the template using a high fidelity DNA polymerase (Fusion high fidelity, ThermoFisher Scientific), according to the manufacturer's instructions (DNA denaturation at $95^{\circ} \mathrm{C}$ for $2 \mathrm{~min}$ followed by 25 cycles of $95^{\circ} \mathrm{C}$ for $10 \mathrm{~s}, 55^{\circ} \mathrm{C}$ for $20 \mathrm{~s}$ and $72^{\circ} \mathrm{C}$ for $30 \mathrm{~s}$ ) and using primer pairs containing EcoRV and XhoI restriction sites at their $5^{\prime}$ and $3^{\prime}$ ends, respectively, as described in table S2. The PCR fragments were digested with the corresponding restriction enzymes and cloned in pET30a $(+)$ at the same unique restriction sites found in the polylinker. The amplified CDS and their fusion in-frame with the series of tags located in the $\mathrm{N}$-terminal of the recombinant proteins, including a $\mathrm{His}_{6}$-tag, were confirmed by double-stranded sequencing using T7P and T7TERM primers (Beckman Coulter Genomics). Because of the codon usage bias in archaea, both proteins were expressed in the E. coli Rosetta (DE3) strain encoding rare tRNA genes, a strategy which has proved successful for numerous archaeal proteins. ${ }^{14,15}$ E.coli Rosetta (DE3) strain cells were 
transformed with the individual expression plasmid and were grown overnight at $37^{\circ} \mathrm{C}$ with shaking in $5 \mathrm{~mL}$ LB media containing $25 \mu \mathrm{g} / \mathrm{mL}$ kanamycin and $30 \mu \mathrm{g} / \mathrm{mL}$ chloramphenicol. The cultures were transferred into $500 \mathrm{~mL}$ (1:100 dilution) LB media supplemented with 25 $\mu \mathrm{g} / \mathrm{mL}$ kanamycin and $30 \mu \mathrm{g} / \mathrm{mL}$ chloramphenicol in $2 \mathrm{~L}$ Erlenmeyer flasks until the $\mathrm{OD}_{600}$ reached 0.5-0.6. The $\mathrm{His}_{6}$-tagged TGAM_1277 and TGAM_1653 recombinant proteins were expressed for $4 \mathrm{~h}$ at $37^{\circ} \mathrm{C}$ after induction with $1 \mathrm{mM}$ IPTG (isopropyl $\beta$-D-1thiogalactopyranoside). Cells were harvested by centrifugation and resuspended in $8 \mathrm{~mL}$ buffer A (20 mM Tris-HCl pH 7.5, 1 mM NaCl, 1 mM DTT, 20 mM imidazole), supplemented with $300 \mu \mathrm{L}$ of a protease inhibitor cocktail for bacterial cells (Sigma Aldrich), and finally stored at $-80^{\circ} \mathrm{C}$ overnight.

\section{Purification of TGAM_1277 and TGAM_1653 recombinant glycosylases}

After thawing on ice, E. coli cells were lyzed with an Eaton Press at a pressure of 10,000 psi, and the resulting extracts were sonicated for $2 \times 15 \mathrm{~s}$. The protein extracts were centrifuged at $15,000 \mathrm{~g}$ for $30 \mathrm{~min}$ at $4^{\circ} \mathrm{C}$. The soluble proteins were loaded onto His-trap columns (Macherey Nagel) previously equilibrated with buffer A and washed in the same buffer. The recombinant proteins were purified by affinity FPLC (Fast Protein Liquid Chromatography) (Amersham, GE Healthcare) with increasing steps of imidazole (50 mM, $150 \mathrm{mM}, 250 \mathrm{mM}$ ) in the same buffer and dialyzed twice (Spectrumlabs, MWCO $15 \mathrm{kDa}$ ) overnight at $4^{\circ} \mathrm{C}$ against $500 \mathrm{~mL}$ buffer B (20 mM Tris- $\mathrm{HCl}$ pH 7.5, 50\% Glycerol v/v, $200 \mathrm{mM} \mathrm{NaCl,} 1 \mathrm{mM}$ DTT). The purified recombinant proteins were almost 95\% pure as judged by SDS-PAGE analysis (Fig.2). The concentrations of TGAM_1653 and TGAM_1277 were 0.33 and 0.22 $\mathrm{mg} / \mathrm{mL}$, respectively, as estimated by Bradford assays.

\section{DNA glycosylase activity assays}




\section{Oligonucleotides (ODNs)}

In order to perform activity tests, ODNs of the following sequences were used: 5'-CAC TTC GG $^{1}$ A $T^{2}$ CG TGA CTG ATC T-3' (control), where $\mathrm{G}^{1}$ was replaced by 8-oxo-dGuo, and $\mathrm{T}^{2}$ by 1-[2-deoxy- $\beta$-D-erythro-pentofuranosyl]-5-hydroxyhydantoin (5-OH-dHyd) or 1-[2deoxy- $\beta$-D-erythro-pentofuranosyl]-5-hydroxy-5-methylhydantoin (5-OH-5-Me-dHyd). All ODNs, except those containing 8-oxo-dGuo (Eurogentec), were synthesized in-house as previously described. ${ }^{16,17}$ In order to form double stranded ODNs, sequences fully complementary to the control ODN were obtained from Eurogentec, along with three other ODNs presenting $\mathrm{G}$, A or T mismatches opposite the $\mathrm{G}^{1}$ position.

\section{Radiolabeling of ODNs}

ODNs $(10 \mathrm{pmol})$ were $\left[5^{\prime}-{ }^{32} \mathrm{P}\right]$-labeled at their $5^{\prime}$-ends with $10 \mu \mathrm{Ci}\left[\gamma_{-}{ }^{32} \mathrm{P}\right]$ ATP $(10 \mathrm{mCi} / \mathrm{mL}$, Perkin Elmer France) and 1 unit of T4 polynucleotide kinase (10 U/ $\mu \mathrm{L}$, Life Technologies/ Invitrogen) in the supplied "forward" reaction buffer. The labeling reaction was performed at $37^{\circ} \mathrm{C}$ for $1 \mathrm{~h}$. Unincorporated $\left[\gamma-{ }^{32} \mathrm{P}\right]$ ATP was then removed using Illustra MicroSpin $\mathrm{G}-25$ Columns (GE Healthcare) and the $\left[5^{\prime}-{ }_{-}^{32} \mathrm{P}\right]$-labeled strands were finally hybridized with their complementary sequences by incubation at $90^{\circ} \mathrm{C}$ for 3 min followed by slow cooling until room temperature was reached.

\section{Polyacrylamide gel electrophoresis}

The $\left[5^{\prime}-{ }^{32} \mathrm{P}\right]$-labeled ODN duplexes $(100 \mathrm{fmol})$ were incubated with 2 pmol TGAM_1653 or TGAM_1277 proteins in the reaction buffer consisting of $20 \mathrm{mM}$ Tris-HCl, buffered at $\mathrm{pH}$ 7.8 and containing $1 \mathrm{mM}$ EDTA and $150 \mathrm{mM} \mathrm{KCl}$. After $30 \mathrm{~min}$ incubation at $37^{\circ} \mathrm{C}$, the temperature was raised progressively to $65^{\circ} \mathrm{C}$ and the reaction was maintained at this 
temperature for $10 \mathrm{~min}$. In parallel, control experiments with E. coli formamidopyridine DNA $N$-glycosylase (Fpg) (a gift from Dr. B. Castaing, CNRS, Orléans, France) were performed. An incubation of $1 \mathrm{~h}$ at $37^{\circ} \mathrm{C}$ was carried out in the reaction buffer for Fpg. The samples were then denatured by heating for $3 \mathrm{~min}$ at $90^{\circ} \mathrm{C}$ in formamide solution and resolved by electrophoresis on a polyacrylamide gel in denaturing conditions. Signal detection was performed by phosphorimaging with the Personal Molecular Imager system (Bio-Rad).

MALDI-TOF-MS

For MALDI-TOF-MS measurements, ODNs were not radioactively labeled but directly hybridized with their complementary sequence. These duplexes (10 pmol) were incubated with 20 pmol TGAM_1653, TGAM_1277, Fpg or Endo III proteins, in conditions as described above for TGAM_1653 and TGAM_1277. The samples were then desalted with the 50WX8 100-200 Dowex resin (Sigma-Aldrich) and analyzed with a Microflex instrument (Bruker). 


\section{RESULTS}

\section{Basal levels of oxidative DNA damage and quantitation after irradiation}

We first wanted to obtain quantitative data about oxidative DNA damage in $T$. gammatolerans with and without exposure to ionizing radiation. DNA damage was measured in cells that were neither irradiated nor incubated on ice ("basal levels", fig. 3). Cells were also exposed to a $\gamma$-ray dose of either 2.5 or $5.0 \mathrm{kGy}$. The exposure lasted $62.5 \min (2.5 \mathrm{kGy})$ or $125 \mathrm{~min}(5.0 \mathrm{kGy})$, and was performed on ice to avoid a significant increase of temperature. Cells were then either immediately collected after irradiation or incubated in fresh medium for $1 \mathrm{~h}$ before being processed. For each condition, nonirradiated controls were prepared in parallel and stored on ice during irradiation. Extraction protocols were carefully optimized, on the basis of a protocol developed for mammalian cells, ${ }^{18}$ to obtain DNA solutions suitable for HPLC-MS/MS measurement of nucleosides and to avoid artifactual oxidation of DNA, which may lead to an overestimation of damage levels.

In these conditions, 8-oxo-dGuo basal levels in T. gammatolerans $(9.2 \pm 0.9$ 8-oxo-dGuo/10 6 nucleosides) were more abundant than in nonirradiated cells stored on ice, which presented a minimum of $4.2 \pm 0.5$ 8-oxo-dGuo/ $10^{6}$ nucleosides for the $5.0 \mathrm{kGy} / 0 \mathrm{~h}$ control and a maximum of $8.4 \pm 1.4$ 8-oxo-dGuo/ $10^{6}$ nucleosides for the $2.5 \mathrm{kGy} / 1 \mathrm{~h}$ control. Irradiated cells exhibited higher levels of DNA lesions than the corresponding controls (Fig. 3), particularly at $5.0 \mathrm{kGy}$, with an increase from $4.2 \pm 0.58$-oxo-dGuo $/ 10^{6}$ nucleosides for controls to $24.2 \pm 8.0$ 8-oxo-dGuo/ $10^{6}$ nucleosides for irradiated cells ( $p<0.05$, MannWhitney). The $1 \mathrm{~h}$ incubation of irradiated cells in a fresh medium was associated with a decrease in 8-oxo-dGuo mean values, which was only significant after $5.0 \mathrm{kGy}$ treatment, 
falling to $9.7+/-2.9$ 8-oxo-dGuo/ $10^{6}$ nucleosides. In control cells, incubation in fresh medium was associated with a slight but statistically significant increase of oxidized purines: from 5.1 +/- 1.2 8-oxo-dGuo/ $10^{6}$ nucleosides to 8.4 +/- 1.4 8-oxo-dGuo/ $10^{6}$ nucleosides for $2.5 \mathrm{kGy}$ controls and from $4.2+/-0.5$ 8-oxo-dGuo/ $10^{6}$ nucleosides to $6.5+/-1.18$-oxo-dGuo $/ 10^{6}$ nucleosides for $5.0 \mathrm{kGy}$ controls.

The $5^{\prime}, 8$-cyclonucleosides ( $5^{\prime} R$ and $5^{\prime} S$ diastereomers of 5',8-cyclodAdo and 5',8-cyclodGuo) were also measured in the same experimental conditions but chromatograms resulting from these analyses did not show detectable peaks, indicating the absence of these DNA alterations or rates below the limit of detection of our methods, which, during this experiment, was estimated at 1.0 lesion $/ 10^{6}$ nucleosides.

\section{Proteomic detection of TGAM_1277 and TGAM_1653, and transcriptional expression of the corresponding genes.}

We focused on two putative BER enzymes identified in the genome of T. gammatolerans: TGAM_1277 and TGAM_1653, which have been annotated as a putative endoIII and a predicted 8-oxoG glycosylase, respectively. We analyzed their occurrence and possible regulation in cells by combining proteomic and transcriptomic approaches. A recent shotgun proteomic survey has been conducted for T. gammatolerans cells subjected to a $5.0 \mathrm{kGy} \gamma$ irradiation dose and the corresponding control without irradiation. ${ }^{19}$ We extracted from the data deposited to the ProteomeXchange Consortium (dataset identifier PXD000402) the spectral counts for the TGAM_1277 and TGAM_1653 proteins in order to evaluate the presence of both proteins. The former was detected and validated through two proteotypic peptides ([134-CANIVLAYGFGR-145] and [215-ELCPYAKGLVR-225]) while the latter was detected by means of a unique peptide ([217-AEETGIPPLHIDSILWPVLGGK-239]) in 
this shotgun survey. As estimated by the normalized spectral abundance factor (NSAF) obtained by normalizing spectral counts with the molecular weight of each protein, ${ }^{20}$ TGAM_1277 (NSAF 0.22) and TGAM_1653 (NSAF 0.10) were slightly less abundant compared to TGAM_1679, the reverse gyrase (NSAF 0.95), and in any case present in fairly low amounts compared to the whole set of detected proteins.

We monitored by real-time RT-PCR the expression of their corresponding genes, TGAM_1277 and TGAM_1653, in control conditions and following $\gamma$-irradiation. For $\gamma$ irradiation, exponentially growing cells were exposed to 2.5 or $5.0 \mathrm{kGy}$ and collected immediately (T0) or incubated post irradiation in fresh VSM medium at $85^{\circ} \mathrm{C}$ for 60 or 120 min (T1, T2, see methods). At both doses, $100 \%$ survival had previously been observed. ${ }^{5}$ Expression profiles of both genes in these conditions are shown in Fig. 4. For TGAM_1277, we observed a comparable relative expression in control conditions and in cells immediately collected after irradiation (T0; 0.03). A slight increase (two-fold) of the relative expression could be detected 1 and $2 \mathrm{~h}(\mathrm{~T} 1, \mathrm{~T} 2)$ after a dose of $2.5 \mathrm{kGy}$. Interestingly, exposure to a higher dose (5.0 kGy) led to a significant upregulation (three-fold) as measured $2 \mathrm{~h}$ after irradiation (T2). For TGAM_1653, a similar relative expression was revealed when nonirradiated cells and cells collected immediately after irradiation were compared (0.110.12). Our data show that the basal relative expression of $T G A M_{-} 1653(0.11-0.12)$ was higher than with TGAM_1277(0.03). However, TGAM_1653 relative expression remained stable following $\gamma$-irradiation at a $2.5 \mathrm{kGy}$ dose and only a weak upregulation could be measured after $2 \mathrm{~h}(\mathrm{~T} 2)$ for a $5.0 \mathrm{kGy}$ irradiation.

\section{Activity of recombinant TGAM_1653 and TGAM_1277}


To characterize their biochemical activities, the two glycosylases were produced in Escherichia coli in fusion with a $\mathrm{His}_{6}$-tag in the N-terminal domain of the protein, as several glycosylases contain a zinc finger motif in their C-terminal domain. We decided to not remove the 48-amino-acid N-terminal extension by proteolysis as our data showed that it does not disrupt protein activities (see hereafter). The excision activities of the recombinant TGAM_1653 and TGAM_1277 proteins were assessed at a temperature increasing from $37^{\circ} \mathrm{C}$ to $65^{\circ} \mathrm{C}$ by means of an electrophoretic cleavage assay using double-stranded and ${ }^{32} \mathrm{P}$-labeled ODNs. DNA lesions inserted into the substrates were: i) 8-oxo-dGuo which is a model of oxidized purine, ii) 5-OH-dHyd, and iii) 5-OH-5-Me-dHyd, the latter two being models of oxidized pyrimidines. For this experimental set-up, the bacterial Fpg enzyme, which is known to have a glycosylase activity toward 8-oxo-dGuo, 5-OH-dHyd and 5-OH-5-Me-dHyd, was used as a positive control.

TGAM_1653 was only able to cleave probes containing 8-oxo-dGuo, whereas TGAM_1277 showed a broader substrate specificity by reacting with the three lesions (Fig. 5A). The effect of the opposite base on glycosylase activity toward 8-oxoG (8-oxo-7,8-dihydroguanine, the oxidized base) was also evaluated using four probes with the four different bases in front of the altered position (Fig. 5B). As already shown by Tchou et al., ${ }^{21}$ Fpg activity is partially inhibited by an 8-oxoG:A mismatch. Once again, TGAM_1277 presented a broad activity in contrast to TGAM_1653, the latter being less efficient when confronted with DNA containing 8-oxo-G:A and 8-oxoG:G pairs whereas TGAM_1277 activity was only weakly affected by the opposite base of the lesion.

The gels in Fig. 5A display different sizes of short excision products. For a given enzyme tested for different lesions this phenomenon is simply explained by the different localizations of DNA modifications within the probe sequences. However, this difference in migration was 
also noted for one given lesion cleaved by different enzymes: fragments generated by

TGAM_1277 with hydantoin lesions exhibited higher molecular weights than others produced with Fpg. Regarding 8-oxo-dGuo, fragments obtained with TGAM_1653 and TGAM_1277 were also of higher molecular weight than the cleavage products of Fpg. As this observation could probably be explained by differences in excision mechanisms, we used MALDI-TOF MS to obtain further insight. This methodology allows a precise determination of the size of the cleavage products, hence providing complementary details about repair mechanisms. ${ }^{22}$ Regarding the excision process of both T. gammatolerans enzymes, our hypothesis was that a $\beta$-elimination occurs while, in contrast, Fpg is known to act as a $\beta, \delta$-elimination enzyme. ${ }^{23}$ Both possible elimination processes are described in Fig. 6.

In our experiments, Fpg and endoIII were used as controls for $\beta, \delta$-elimination of 8 -oxo-dGuo and $\beta$-elimination of 5-OH-5-Me-dHyd, respectively. Experimental MALDI-TOF MS spectra acquired on the products of Fpg, and recombinant TGAM_1653 and TGAM_1277 excision, are shown in Figs. 7 and 8. 8-oxo-dGuo repair by Fpg was first characterized by the absence of peak 1 corresponding to 8-oxo-dGuo-containing strands. This was indicative of a total cleavage of the substrate by the enzyme. The presence of peaks $3([\mathrm{M}-\mathrm{H}]-=4332.9 \mathrm{Da}$; calculated $=4332.8 \mathrm{Da})$ and $4([\mathrm{M}-\mathrm{H}]-=2135.6 \mathrm{Da}$; calculated $=2135.4 \mathrm{Da})$ is characteristic of the $\beta, \delta$-elimination process. For TGAM_1653 tested on 8-oxo-dGuo substrates, the absence of peak 1 proves a complete cleavage whereas the presence of peaks $3([\mathrm{M}-\mathrm{H}]-=$ 4332.5 Da) and $5([\mathrm{M}-\mathrm{H}]-=2233.9 \mathrm{Da}$; calculated $=2233.4 \mathrm{Da})$ confirms a $\beta$-elimination mechanism. The MALDI-TOF MS spectrum of TGAM_1277 activity revealed that peak 1 was clearly visible, indicating that in our experimental conditions, this enzyme did not cut all the available substrate. TGAM_1277 was therefore considered as less active than Fpg and TGAM_1653, confirming the results obtained with electrophoretic gels (Fig. 5). Considering 
the cleavage products, we were able to detect peak $\mathbf{3}$ but not peak $\mathbf{4}$, thus characterizing a $\beta$ elimination process. Actually, the presence of peak $6([\mathrm{M}-\mathrm{H}]-=2251.9 \mathrm{Da}$; calculated $=$ 2251.5 Da) probably reveals a hydration product of the $\alpha-\beta$-unsaturated ketone, which should have been represented by fragment . $^{24}$ We can therefore assume that TGAM_1277 uses a $\beta$ elimination process.

The same principle was applied to the cleavage of ODNs containing 5-OH-5-Me-dHyd (Fig. 8). The MALDI-TOF MS profile corresponding to our control endoIII confirms its $\beta$ elimination activity with the presence of peak $3([\mathrm{M}-\mathrm{H}]-=3714.9 \mathrm{Da}$; calculated $=3715.4$ Da) and hydrated product $6([\mathrm{M}-\mathrm{H}]-=2893.7 \mathrm{Da}$; calculated $=2893.9 \mathrm{Da})$. The $\beta, \delta-$ elimination exhibited by Fpg is demonstrated again by the presence of peaks $3([\mathrm{M}-\mathrm{H}]-=$ 3715.6 Da; calculated $=3715.4 \mathrm{Da})$ and $4([\mathrm{M}-\mathrm{H}]-=2776.5 \mathrm{Da}$; calculated $=2777.8 \mathrm{Da})$. The MS profile of TGAM_1277 is very close to that obtained with endoIII: product 3 at $3714.8 \mathrm{Da}$ and product 6 at $2893.5 \mathrm{Da}$ indicating $\beta$-elimination. The only difference with endoIII is the absence of peak 1, indicating a more efficient cleavage. TGAM_1653 is not associated with short fragments, a characteristic that again indicates its absence of activity on 5-OH-5-MedHyd.

In conclusion, TGAM_1653 and TGAM_1277 both exhibit a $\beta$-elimination cleavage activity. TGAM_1653 is only able to cleave 8-oxo-dGuo whereas TGAM_1277 is also able to cut ODNs containing pyrimidine lesions (5-OH-dHyd and 5-OH-5-Me-dHyd). It is worth noting that ODN substrates containing 8-oxodA and 5',8-cyclonucleosides were also tested but did not show detectable excisions (data not shown). 


\section{DISCUSSION}

\section{T. gammatolerans shows a basal level of 8-oxo-dGuo that is enhanced by high doses of $\gamma$ - irradiation, but rapidly decreases post exposure}

Measurement of oxidative base damage in cellular DNA is a rather commonly used biomarker of oxidative stress but has for a long time been associated with questionable results due to possible overestimation related to technical artifacts. By using the most appropriate preanalytical precautions, as well as sensitive and specific methods such as HPLCelectrochemical detection and, more recently, HPLC-MS/MS, it is now accepted that background levels of 8-oxo-dGuo in human cells such as lymphocytes are below the threshold of 1 lesion per $10^{6}$ nucleosides (4 lesions per $10^{6}$ guanines). ${ }^{25,26}$ This level corresponds to approximately 10,000 8-oxo-dGuo per single nucleus. ${ }^{27}$ Using HPLC-MS/MS, 8-oxo-dGuo measurements in E. coli DNA carried out by our team showed basal rates of $2.6(+/-0.9) 8$ oxo-dGuo per $10^{6}$ nucleosides (unpublished data). In the present study, basal levels measured in T. gammatolerans grown in laboratory experimental conditions were 9.2 (+/- 0.9) 8-oxodGuo per $10^{6}$ nucleosides, which represents approximatively 18 8-oxo-dGuo per chromosome (T. gammatolerans is a polyploid organism for which the mean number of chromosome copies has not been determined yet). While an overwhelming proportion of published studies reporting 8-oxo-dGuo rates have been performed using mammalian cells, the only relevant work comparable with ours was carried out using the archaeon Halobacterium salinarum. ${ }^{28}$ In this halophilic organism, a basal level of 2.1 8-oxoG (oxidized base) per $10^{6}$ bases was observed by means of gas chromatography coupled to mass spectrometry. Two other oxidative purine lesions were assessed in the same study: 4,6-diamino-5formamidopyrimidine (FapyAde) and 2,6-diamino-4-hydroxy-5-formamidopyrimidine (FapyGua), which showed concentrations of 0.3 and 0.9 lesion per $10^{6}$ bases, respectively. 
Elevated rates of 8-oxo-dGuo found in T. gammatolerans could be related to the growth conditions, and more specifically to the temperature. Indeed, the optimal growth temperature for this hyperthermophilic organism $\left(85^{\circ} \mathrm{C}\right)$ was chosen for the experimental work presented here, while lower temperatures were used in other studies: $37^{\circ} \mathrm{C}$ for human cells and $42^{\circ} \mathrm{C}$ for H. salinarum. Heat-induced formation of oxidized guanine, at least in vitro, has been reported. ${ }^{29}$ Because nonirradiated cells stored on ice presented only 4.2 8-oxo-dGuo lesions per $10^{6}$ nucleosides, this hypothesis of heat-induced damage formation is reinforced. This was confirmed by the result obtained with nonirradiated cells incubated for $1 \mathrm{~h}$ at $85^{\circ} \mathrm{C}$ in culture medium, which also showed a significant increase in their 8-oxo-dGuo content. It can be highlighted here that another type of DNA damage, abasic sites, was also found at elevated levels in Pyrococcus abyssi: between 25 (exponential phase) and 42 (stationary phase) abasic sites per 100,000 base pairs in the genome of this hyperthermophilic archaeon versus 2 and 4, respectively, abasic sites per 100,000 base pairs in E. coli. ${ }^{30}$

In order to study DNA damage in the context of exposure to ionizing radiation, $T$. gammatolerans samples were subjected to high doses of $\gamma$-radiation. Levels of 8-oxo-dGuo measured in cells harvested immediately after treatment significantly increased. The corresponding yields of radiation-induced modifications are 2.8 8-oxo-dGuo/10 12 nucleosides/Gy at $2.5 \mathrm{kGy}$ and 4.0 8-oxo-dGuo/10 12 nucleosides/Gy at $5.0 \mathrm{kGy}$. Again, measurements of 8-oxo-dGuo after irradiation have previously been measured mainly using eukaryotic cells, ${ }^{25,31-33}$ and with doses lower than 500 Gy. In the THP1 malignant monocyte cell line, HPLC-MS/MS analysis indicated a damage yield reaching 20 8-oxo-dGuo/109 nucleosides/Gy ( 200 to 300 8-oxo-dGuo / cell / Gy). ${ }^{31}$ Kish et $a l .{ }^{28}$ analyzed the oxidized base, 8-oxoG, after exposure of the archaeon $H$. salinarum at $0,2.5,5.0$ and $7.5 \mathrm{kGy}$. A plateau was reached at $2.5 \mathrm{kGy}$, for which the levels were 2.18 -oxoG/10 ${ }^{6}$ bases and 3.1 8oxoG/ $10^{6}$ bases at 0 and $7.5 \mathrm{kGy}$, respectively $\left({ }^{60} \mathrm{Co}\right.$ gamma source), corresponding to less 
than 1 lesion/10 12 bases/Gy. Therefore, this archaeon also showed yields of oxidized guanine formation far below those observed in human cells. These very low yields may be explained by a cellular redox environment and low $\mathrm{O}_{2}$ levels that prevent the formation of oxidative DNA damage, or by detoxification systems. ${ }^{4}$ In the same halophilic organism, Robinson et $a l .{ }^{34}$ observed an increase of FapyGua levels at $2.5 \mathrm{kGy}$ but no significant progression of 8oxoG.

Apart from a potential role of DNA repair enzymes, low levels of oxidative DNA damage observed in T. gammatolerans after irradiation may be linked to mechanisms such as highly constitutively expressed detoxification systems. For example, the genome of this archaeon is containing sequences related to proteins known to decrease oxidative stress such as a thioredoxin reductase (TGAM_0180), a glutaredoxin-like protein (TGAM_1302) and 2 peroxiredoxins (TGAM_1253 and TGAM_1220). ${ }^{2,4}$

T. gammatolerans cells exposed to $5.0 \mathrm{kGy}$ radiation showed a significant decrease of 8-oxo$\mathrm{dGuo}$ after $1 \mathrm{~h}$ recovery in culture medium, whereas this phenomenon was not significant at the lower levels of oxidative DNA damage observed at $2.5 \mathrm{kGy}$. Studies performed with $H$. salinarum indicated a decrease of FapyGua, FapyAde and 8-oxoG rates after a $2.5 \mathrm{kGy}$ irradiation and $2 \mathrm{~h}$ recovery compared with nonexposed organisms (rates after $1 \mathrm{~h}$ recovery were not measured). ${ }^{28}$ This decrease of 8 -oxo-dGuo one hour after the end of irradiation may contribute to the resistance of $T$. gammatolerans. It may be explained by DNA repair systems or other factors limiting the extent of DNA damage.

\section{Cyclonucleoside formation in T. gammatolerans DNA is questionable}

Cyclonucleosides (in this study, cyclopurines) are classified as complex oxidative DNA lesions presenting, in the same nucleotide, a covalent bond between the $\mathrm{C} 8$ of the base and the $\mathrm{C}^{\prime}$ ' of the 2-deoxyribose. In vitro studies show that these bulky lesions are mutagenic ${ }^{35}$ and 
interfere with replication and transcription. ${ }^{36-38}$ Contrary to small oxidative DNA damage such as oxidized bases, it also appears that cyclopurines are repaired by the nucleotide excision repair system and not by BER enzymes. In parallel to these mechanistic results, measurements of cyclopurine rates in DNA extracted from eukaryotic cultured cells and tissues have been performed by a limited number of research teams. In spite of similar methods, i.e. isotope dilution technique in combination with HPLC coupled to mass spectrometry, discrepancies can be noted among the concentrations reported in the literature. In THP1 human monocytes, Belmadoui et al. ${ }^{9}$ did not detect $5^{\prime} R$ and $5^{\prime} S$ diastereomers of 5 5'8-cyclodAdo above the detection limit of the method, which was 0.1 lesion per $10^{9}$ nucleosides. In rodent tissues, the team of Wang measured basal levels of $5^{\prime} R$ and $5^{\prime} S$ diastereomers of 5',8-cyclodAdo and 5',8-cyclodGuo superior to 0.1 lesion per $10^{6}$ nucleosides. ${ }^{39-41}$ In the work reported here, we did not show the presence of detectable cyclopurines in T. gammatolerans cells in any of the conditions tested. Indeed, even exposure to $5.0 \mathrm{kGy}$ radiation did not lead to a signal above our limit of detection, estimated at 1 lesion $/ 10^{6}$ nucleosides for this experiment (the limit of detection is dependent on the quantity of DNA available for the analysis). In our case, another favorable factor for the detection of cyclonucleosides should be the anaerobic growth conditions of $T$. gammatolerans. Cyclonucleosides are indeed more prone to formation at low $\mathrm{O}_{2}$ concentrations. ${ }^{9}$ Taken together, these data indicate that cyclonucleoside formation in living cells, T. gammatolerans in our case, may occur at very low levels, if at all.

\section{TGAM_1653 and TGAM_1277 are slightly upregulated after heavy radiation exposure}

Data extracted from proteomic results indicated the presence at low levels of BER enzymes TGAM_1653 and TGAM_1277 in nonirradiated and irradiated cells. No difference between 
these two conditions was noted in terms of protein abundance, but the sensitivity of the MS shotgun approach is not sufficient to detect moderate variations. The expression of the corresponding genes was confirmed by RT-PCR. For TGAM_1277, the main difference appeared $2 \mathrm{~h}$ after a $5.0 \mathrm{kGy}$ irradiation, with an increase of the relative expression from 0.03 (T0) to 0.09. TGAM_1653 basal mRNA levels were higher than those of TGAM_1277, but the regulation of the transcription of this gene was less sensitive to irradiation. The expression of BER enzymes before exposure to ionizing radiation is not surprising since extremophiles need constitutive protective mechanisms to deal with their harsh growth conditions. The DNA damage analysis reported here shows the presence of an elevated amount of oxidized bases in basal conditions that may require a sufficient amount of DNA repair enzymes. The weak or absent upregulation of several DNA repair genes after an exposure to genotoxic stress has already been observed in other archaea. Pyrococcus furiosus subjected to $2.5 \mathrm{kGy}{ }^{60} \mathrm{Co} \gamma$-rays did not show changes in mRNA levels for BER glycosylases but presented a moderate upregulation of $\mathrm{radA}$ (DNA repair by homologous recombination) and of a DNA repair gene cluster possibly involved in translesion synthesis. ${ }^{42} \mathrm{UV}$ irradiation of hyperthermophilic Sulfolobus archaea did not lead to overexpression of DNA repair genes, including BER genes. $^{43}$

It is also recognized that a majority of DNA repair factors are constitutively expressed in eukaryotic cells. ${ }^{44}$ At the protein level, the expression of BER factors is not massively induced, even after significant exposure to genotoxic agents. ${ }^{45}$ We also observed that 8-oxodGuo produced after a $\gamma$-ray exposure are repaired within the first hour of recovery, whereas maximum levels of TGAM_1277 and TGAM_1653 transcripts were measured at $2 \mathrm{~h}$. We can suggest that newly synthesized enzymes are produced (i) to repair other types of more persistent oxidative DNA damage or (ii) to reconstitute the pool of constitutive enzymes that has probably been, at least partly, altered by irradiation. This degradation of BER factors by 
$\gamma$-rays has already been shown to occur in human cells ${ }^{46}$ at much lower doses (up to 60 Gy) compared to those in the present study. Finally, it is worth mentioning that our observations are mainly based on mRNA levels. It would be interesting to complement them with further data related to proteins, as well as their post-translational modifications, which are known to play an important role in the regulation of BER in eukaryotes. ${ }^{47}$

\section{TGAM_1653 excises 8-oxoG, TGAM_1277 excises 8-oxoG and hydantoin lesions. Both possess a $\beta$-elimination activity.}

According to our study, TGAM_1277 and TGAM_1653 are bifunctional BER enzymes: they are able (i) to recognize and remove oxidized bases by cleaving the $N$-glycosyl bond between the deoxyribose and the damaged base, and (ii) to cleave the resulting abasic site leading to a single-strand break (lyase activity). More precisely, we demonstrated that both enzymes cleave the abasic site via a $\beta$-elimination process resulting in a 3 '-phospho- $\alpha, \beta$-unsaturated aldehyde and in a 5'-phosphate extremity (Fig. 6).

TGAM_1277 was annotated as a putative type III endonuclease. ${ }^{2}$ Indeed, we have shown here that this enzyme shares the common features of the bacterial BER enzyme, i.e.

bifunctionality, a $\beta$-elimination process and the capacity to repair hydantoin lesions (5OHdHyd and 5-OH-5-Me-dHyd). ${ }^{22,48}$ By contrast with bacterial EndoIII, we found that TGAM_1277 is also able to cleave 8-oxo-dGuo, particularly when mispaired with T or G. This variety of substrates is also found for the E. coli enzyme Fpg, which presents a $\beta, \delta$ elimination mechanism.

When compared with TGAM_1277, TGAM_1653 shows a more restrictive panel of substrates as it does not cleave oxidized pyrimidines and is not as efficient as TGAM_1277 in cleaving 8-oxo-dGuo when mispaired, particularly to A and G. This profile of substrates is 
close to that noted in other studies for the human BER enzyme, hOGG1 (human 8-oxoG DNA Glycosylase I). ${ }^{49,50}$

As for TGAM_1277 and TGAM_1653, the 8-oxoG DNA glycosylase from the sulfatereducing archaeon Archeoglobus fulgidus (Afogg) presents a bifunctional and $\beta$-elimination mechanism. ${ }^{51}$ This protein is able to repair 8-oxo-dGuo when associated with $\mathrm{C}$ and $\mathrm{G}$, and to a lesser extent when mispaired with T and A. Pyrobaculum aerophilum 8-oxoG DNA glycosylase (Pa-AGOG), a formative member of a new DNA glycosylase family, also demonstrated a bifunctional and $\beta$-elimination process. ${ }^{10}$ Structural studies indicated that this enzyme has an HhH-GPD motif (helix-hairpin-helix associated with a glycine-proline-rich sequence, followed by a conserved aspartate) that is significantly different in terms of amino acid sequence compared to that of hOGG1, but similar in terms of tridimensional structure.

An alignment of the Pa-AGOG, TGAM_1277 and TGAM_1653 polypeptides is shown in Fig. 9. Pa-AGOG and TGAM_1653 display only $25 \%$ sequence identity and $43 \%$ similarity, but $P$. aerophilum and $T$. gammatolerans belong to two separate phyla of Archaea (Crenarcheota vs Euryarcheota). However, residues playing an important role for catalytic activity (K140, D172) or substrate recognition (Q31, K147, D218, W222) in Pa-AGOG ${ }^{10,52}$ are conserved in TGAM_1653 and not in TGAM_1277 (Fig. 9). This suggests that Pa-AGOG and TGAM_1653 may belong to the same glycosylase family, even if some discrepancies are revealed. Pa-AGOG is able to repair 8-oxo-dGuo when paired with $\mathrm{C}$ and $\mathrm{A}$ but presented a stronger efficiency for 8-oxoG:G mismatches. ${ }^{52} \mathrm{We}$ showed here that this strong capacity to cleave 8-oxoG:G pairs was also shared by TGAM_1277, TGAM_1653 and Afogg. It could be interesting for hyperthermophilic organisms to cleave 8-oxoG:G lesions generated by the incorporation of free 8-oxodGMP opposite to a G, this phenomenon probably being favored by high temperatures. ${ }^{10,53}$ Neither Afogg nor Pa-AGOG were tested for their capacity to repair damaged pyrimidines, making the comparison with $T$. gammatolerans enzymes 
difficult to extend further. We also tested cyclonucleosides as potential substrates: TGAM_1277 and TGAM_1653 did not show cleavage activity. Previously published experiments, based on eukaryote whole-cell extracts or purified enzymes, have already demonstrated that BER does not deal with these complex oxidative DNA lesions. ${ }^{54-57}$ In order to obtain a comprehensive picture of BER in T. gammatolerans, complementary experiments have to be performed on other putative BER factors highlighted by our previous genomic and proteomic screenings. ${ }^{2}$ At least seven candidates, annotated as "Uracil-DNA glycosylase”, "Base excision DNA repair protein, HhH-GPD superfamily”, "AP endonuclease family 2" or "endonuclease V", have been identified. Study of these archaeal enzymes can lead to the discovery of original DNA repair activities, as revealed by the recent characterization of EndoQ found in Pyrococcus furiosus and T. kodakarensis. ${ }^{58}$ This endonuclease is able to repair deaminated bases generated for example by ionizing radiation or elevated temperatures. Glycosylases and lyases are the very first enzymes involved in the BER system. It may also be interesting to study other BER proteins involved in the later stages of the pathway. For example, it would be relevant to focus attention on BER factors processing single strand breaks as these latter lesions are also generated by ionizing radiation. ${ }^{47}$ Finally, a further characterization of enzymatic activities including parameters such as thermostability or influence of $\mathrm{pH}$, would be interesting, particularly for a potential use of these proteins as new tools for research and applied biotechnologies laboratories. ${ }^{59}$

\section{Conclusion}

This work established that the basal level of the oxidative DNA damage, 8-oxo-dGuo, in $T$. gammatolerans is higher than that reported for mammalian cells. As expected, this level of damage increased with high doses of ionizing radiation. Remarkably, the yield of lesions 
generated was much lower than those observed in human cell lines. One hour post irradiation, the rate of oxidative DNA damage was the same as the control background, indicating that the repair process is rather rapid. TGAM_1277 and TGAM_1653 BER enzymes were slightly upregulated after heavy radiation exposure. As shown here, these enzymes are able to initiate DNA repair of oxidized pyrimidines (TGAM_1277) and guanines (TGAM_1277 and TGAM_1653). Therefore, T. gammatolerans is at any time prepared to counteract DNA oxidation with this protein arsenal. While the search for cyclonucleosides showed no significant levels above technical background, other original DNA lesions such as clusters of damage $^{33,60}$ would be interesting to identify in radiotolerant organisms such as $T$.

gammatolerans. Regarding DNA repair proteins such as TGAM_1277 and TGAM_1653, structural studies with the enzymes alone and with their DNA substrates would provide additional data about recognition and cleaving mechanisms.

Further molecular studies on proteins from T. gammatolerans, one of the most radiotolerant organisms currently known, should bring valuable information on DNA repair in archaea. Moreover, deciphering the mechanisms explaining its extraordinary resistance to extreme conditions may have potential applications in biotechnology. ${ }^{61}$ 


\title{
FUNDING INFORMATION
}

This study was supported by the Agence Nationale de la Recherche (ANR-12-BSV6-0012$01)$.

\section{ACKNOWLEDGEMENTS}

We would like to thank Dr. B. Castaing (Orléans, France) for providing Fpg and advice. We also thank Dr. V. Favaudon (Institut Curie, Orsay) for access to the ${ }^{137}$ Cs gamma irradiation source.

\section{SUPPORTING INFORMATION}

Table S1: list of oligonucleotides used for quantitative real-time RT-PCR. Table S2: cloning and expression of TGAM_1277 and TGAM_1653 - primer pairs used to amplify coding sequences from total genomic DNA. This material is available free of charge via the Internet at http://pubs.acs.org.

\begin{abstract}
ABBREVIATIONS
5',8-cyclodAdo, 5',8-cyclo-2'-deoxyadenosine; 5',8-cyclodGuo, 5',8-cyclo-2'deoxyguanosine; 5-OH-5-Me-dHyd, 1-[2-deoxy- $\beta$-D-erythro-pentofuranosyl]-5-hydroxy-5methylhydantoin; 5-OH-dHyd, 1-[2-deoxy- $\beta$-D-erythro-pentofuranosyl]-5-hydroxyhydantoin; 8-oxo-dGuo, 8-oxo-2'-deoxyguanosine; 8-oxoG, 8-oxo-7,8-dihydroguanine; Afogg, 8-oxoG DNA glycosylase from the sulfate-reducing archaeon Archeoglobus fulgidus; BER, Base Excision Repair; CDS, Coding DNA Sequence; Endo III, type III endonuclease; ESI, ElectroSpray Ionisation; FapyAde, 4,6-diamino-5-formamidopyrimidine; FapyGua, 2,6diamino-4-hydroxy-5-formamidopyrimidine; Fpg, formamidopyridine DNA N-glycosylase; FPLC, Fast Protein Liquid Chromatography; HhH-GPD motif, helix-hairpin-helix associated
\end{abstract}


with a glycine-proline-rich sequence, followed by a conserved aspartate; hOGG1, human 8oxoG DNA Glycosylase 1; HPLC-MS/MS, HPLC coupled to tandem mass spectrometry; kGy, kiloGray; MALDI-TOF, Matrix-Assisted Laser Desorption Ionization - Time Of Flight; $\mathrm{Mb}$, megabase; NSAF, normalized spectral abundance factor; ODN, oligodeoxynucleotide; Pa-AGOG, Pyrobaculum aerophilum 8-oxoG DNA glycosylase; radA, DNA repair by homologous recombination; ROS, Reactive Oxygen Species; rpoB, DNA-directed RNA polymerase subunit B; RT-PCR, Reverse Transcription PCR; Tbp, TATA box-binding protein 


\section{REFERENCES}

(1) Jolivet, E., L'Haridon, S., Corre, E., Forterre, P., and Prieur, D. (2003) Thermococcus gammatolerans sp. nov., a hyperthermophilic archaeon from a deep-sea hydrothermal vent that resists ionizing radiation. Int.J.Svst.Evol.Microbiol. 53, 847-851.

(2) Zivanovic, Y., Armengaud, J., Lagorce, A., Leplat, C., Guerin, P., Dutertre, M., Anthouard, V., Forterre, P., Wincker, P., and Confalonieri, F. (2009) Genome analysis and genome-wide proteomics of Thermococcus gammatolerans, the most radioresistant organism known amongst the Archaea. Genome Biology 10, R70.

(3) Confalonieri, F., and Sommer, S. (2011) Bacterial and archaeal resistance to ionizing radiation. Cost Chemistry Cm0603-Melusyn Joint Meeting: Damages Induced in Biomolecules by Low and High Energy Radiations 261, 012005.

(4) Webb, K. M., and DiRuggiero, J. (2012) Role of Mn2+ and compatible solutes in the radiation resistance of thermophilic bacteria and archaea. Archaeg 2012, 845756.

(5) Tapias, A., Leplat, C., and Confalonieri, F. (2009) Recovery of ionizing-radiation damage after high doses of gamma ray in the hyperthermophilic archaeon Thermococcus gammatolerans. Extremophiles 13, 333-343.

(6) Cadet, J., Douki, T., and Ravanat, J. L. (2011) Measurement of oxidatively generated base damage in cellular DNA. Mutat.Res. 711, 3-12.

(7) Michaels, M. L., and Miller, J. H. (1992) The GO system protects organisms from the mutagenic effect of the spontaneous lesion 8-hydroxyguanine (7,8-dihydro-8oxoguanine). J.Bacteriol. 174, 6321-6325.

(8) Chatgilialoglu, C., Ferreri, C., and Terzidis, M. A. (2011) Purine 5',8-cyclonucleoside lesions: chemistry and biology. Chem. Soc. Rev. 40, 1368-1382. 
(9) Belmadoui, N., Boussicault, F., Guerra, M., Ravanat, J. L., Chatgilialoglu, C., and Cadet, J. (2010) Radiation-induced formation of purine 5',8-cyclonucleosides in isolated and cellular DNA: high stereospecificity and modulating effect of oxygen. Org Biomol. Chem. 8, 3211-3219.

(10) Sartori, A. A., Lingaraju, G. M., Hunziker, P., Winkler, F. K., and Jiricny, J. (2004) Pa-AGOG, the founding member of a new family of archaeal 8-oxoguanine DNAglycosylases. Nucleic Acids Res. 32, 6531-6539.

(11) Pfaffl, M. W. (2001) A new mathematical model for relative quantification in realtime RT-PCR. Nucleic Acids Res. 29, e45.

(12) Vandesompele, J., De Preter, K., Pattyn, F., Poppe, B., Van Roy, N., De Paepe, A., and Speleman, F. (2002) Accurate normalization of real-time quantitative RT-PCR data by geometric averaging of multiple internal control genes. Genome Biol. 3, RESEARCH0034.

(13) Lagorce, A., Fourcans, A., Dutertre, M., Bouyssiere, B., Zivanovic, Y., and Confalonieri, F. (2012) Genome-wide transcriptional response of the archaeon Thermococcus gammatolerans to cadmium. Plos One 7, e41935.

(14) Armengaud, J., Fernandez, B., Chaumont, V., Rollin-Genetet, F., Finet, S., Marchetti, C., Myllykallio, H., Vidaud, C., Pellequer, J. L., Gribaldo, S., Forterre, P., and Gans, P. (2003) Identification, purification, and characterization of an eukaryotic-like phosphopantetheine adenylyltransferase (coenzyme A biosynthetic pathway) in the hyperthermophilic archaeon Pyrococcus abyssi. L. Biol.Chem. 278, 31078-31087.

(15) Gabant, G., Auxilien, S., Tuszynska, I., Locard, M., Gajda, M. J., Chaussinand, G., Fernandez, B., Dedieu, A., Grosjean, H., Golinelli-Pimpaneau, B., Bujnicki, J. M., and Armengaud, J. (2006) THUMP from archaeal tRNA:m22G10 methyltransferase, a genuine autonomously folding domain. Nucleic Acids Res. 34, 2483-2494. 
(16) Gasparutto, D., Ait-Abbas, M., Jaquinod, M., Boiteux, S., and Cadet, J. (2000) Repair and coding properties of 5-hydroxy-5-methylhydantoin nucleosides inserted into DNA oligomers. Chem. Res. Toxicol. 13, 575-584.

(17) Muller, E., Gasparutto, D., Lebrun, C., and Cadet, J. (2001) Site-specific insertion of the $\left(5 \mathrm{R}^{*}\right)$ and $\left(5 \mathrm{~S}^{*}\right)$ diastereoisomers of 1-[2-deoxy-beta-D-erythro-pentofuranosyl]5-hydroxyhydantoin into oligodeoxyribonucleotides. European J. Org. Chem. 2001, 2091-2099.

(18) Ravanat, J. L., Douki, T., Duez, P., Gremaud, E., Herbert, K., Hofer, T., Lasserre, L., Saint-Pierre, C., Favier, A., and Cadet, J. (2002) Cellular background level of 8-oxo7,8-dihydro-2'-deoxyguanosine: an isotope based method to evaluate artefactual oxidation of DNA during its extraction and subsequent work-up. Carcinogenesis 23, 1911-1918.

(19) Yang, Y. S., Fernandez, B., Lagorce, A., Aloin, V., De Guillen, K. M., Boyer, J. B., Dedieu, A., Confalonieri, F., Armengaud, J., and Roumestand, C. (2015) Prioritizing targets for structural biology through the lens of proteomics: the archaeal protein TGAM_1934 from Thermococcus gammatolerans. Proteomics 15, 114-123.

(20) Christie-Oleza, J. A., Fernandez, B., Nogales, B., Bosch, R., and Armengaud, J. (2012) Proteomic insights into the lifestyle of an environmentally relevant marine bacterium. ISMEJ 6, 124-135.

(21) Tchou, J., Kasai, H., Shibutani, S., Chung, M. H., Laval, J., Grollman, A. P., and Nishimura, S. (1991) 8-oxoguanine (8-hydroxyguanine) DNA glycosylase and its substrate-specificity. Proc. Natl. Acad. Sci.U.S.A. 88, 4690-4694.

(22) D'Ham, C., Romieu, A., Jaquinod, M., Gasparutto, D., and Cadet, J. (1999) Excision of 5,6-dihydroxy-5,6-dihydrothymine, 5,6-dihydrothymine, and 5-hydroxycytosine 
from defined sequence oligonucleotides by Escherichia coli endonuclease III and Fpg proteins: kinetic and mechanistic aspects. Biochemistry 38, 3335-3344.

(23) Bhagwat, M., and Gerlt, J. A. (1996) 3'- and 5'-strand cleavage reactions catalyzed by the Fpg protein from Escherichia coli occur via successive beta- and delta-elimination mechanisms, respectively. Biochemistrv 35, 659-665.

(24) Darwanto, A., Farrel, A., Rogstad, D. K., and Sowers, L. C. (2009) Characterization of DNA glycosylase activity by matrix-assisted laser desorption/ionization time-of-flight mass spectrometry. Anal. Biochem. 394, 13-23.

(25) Frelon, S., Douki, T., Ravanat, J. L., Pouget, J. P., Tornabene, C., and Cadet, J. (2000) High-performance liquid chromatography--tandem mass spectrometry measurement of radiation-induced base damage to isolated and cellular DNA. Chem. Res. Toxicol. 13, 1002-1010.

(26) Gedik, C. M., and Collins, A. (2005) Establishing the background level of base oxidation in human lymphocyte DNA: results of an interlaboratory validation study. EASEB J. 19, 82-84.

(27) Ohno, M., Miura, T., Furuichi, M., Tominaga, Y., Tsuchimoto, D., Sakumi, K., and Nakabeppu, Y. (2006) A genome-wide distribution of 8-oxoguanine correlates with the preferred regions for recombination and single nucleotide polymorphism in the human genome. Genome Res. 16, 567-575.

(28) Kish, A., Kirkali, G., Robinson, C., Rosenblatt, R., Jaruga, P., Dizdaroglu, M., and DiRuggiero, J. (2009) Salt shield: intracellular salts provide cellular protection against ionizing radiation in the halophilic archaeon, Halobacterium salinarum NRC-1.

Environ. Microbiol. 11, 1066-1078. 
(29) Bruskov, V. I., Malakhova, L. V., Masalimov, Z. K., and Chernikov, A. V. (2002)

Heat-induced formation of reactive oxygen species and 8-oxoguanine, a biomarker of damage to DNA. Nucleic Acids Res. 30, 1354-1363.

(30) Palud, A., Villani, G., L'Haridon, S., Querellou, J., Raffin, J. P., and Henneke, G. (2008) Intrinsic properties of the two replicative DNA polymerases of Pyrococcus abyssi in replicating abasic sites: possible role in DNA damage tolerance? Mol. Microbiol. 70, 746-761.

(31) Pouget, J. P., Frelon, S., Ravanat, J. L., Testard, I., Odin, F., and Cadet, J. (2002) Formation of modified DNA bases in cells exposed either to gamma radiation or to high-LET particles. Radiat. Res. 157, 589-595.

(32) Douki, T., Ravanat, J. L., Pouget, J. P., Testard, I., and Cadet, J. (2006) Minor contribution of direct ionization to DNA base damage inducedby heavy ions. Int. J. Radiat.Biol. 82, 119-127.

(33) Regulus, P., Duroux, B., Bayle, P. A., Favier, A., Cadet, J., and Ravanat, J. L. (2007) Oxidation of the sugar moiety of DNA by ionizing radiation or bleomycin could induce the formation of a cluster DNA lesion. Proc. Natl.Acad.Sci.U.S.A. 104, $14032-14037$.

(34) Robinson, C. K., Webb, K., Kaur, A., Jaruga, P., Dizdaroglu, M., Baliga, N. S., Place, A., and Diruggiero, J. (2011) A major role for nonenzymatic antioxidant processes in the radioresistance of Halobacterium salinarum. L.Bacteriol. 193, 1653-1662.

(35) Yuan, B., Wang, J., Cao, H., Sun, R., and Wang, Y. (2011) High-throughput analysis of the mutagenic and cytotoxic properties of DNA lesions by next-generation sequencing. Nucleic Acids Res. 39, 5945-5954.

(36) Abraham, J., and Brooks, P. J. (2011) Divergent effects of oxidatively induced modification to the $\mathrm{C} 8$ of $2^{\prime}$-deoxyadenosine on transcription factor binding: $8,5^{\prime}(\mathrm{S})$ - 
cyclo-2'-deoxyadenosine inhibits the binding of multiple sequence specific transcription factors, while 8-oxo-2'-deoxyadenosine increases binding of CREB and NF-kappa B to DNA. Environ. Mol. Mutagen. 52, 287-295.

Jasti, V. P., Das, R. S., Hilton, B. A., Weerasooriya, S., Zou, Y., and Basu, A. K. (2011) (5'S)-8,5'-Cyclo-2'-deoxyguanosine is a strong block to replication, a potent pol V-dependent mutagenic lesion, and is inefficiently repaired in Escherichia coli. Biochemistrv 50, 3862-3865.

(38) Walmacq, C., Wang, L., Chong, J., Scibelli, K., Lubkowska, L., Gnatt, A., Brooks, P. J., Wang, D., and Kashlev, M. (2015) Mechanism of RNA polymerase II bypass of oxidative cyclopurine DNA lesions. Proc. Natl. Acad. Sci. U.S.A. 112, E410-419.

(39) Wang, J., Clauson, C. L., Robbins, P. D., Niedernhofer, L. J., and Wang, Y. (2012) The oxidative DNA lesions 8,5'-cyclopurines accumulate with aging in a tissuespecific manner. Aging Cell 11, 714-716.

(40) Tilstra, J. S., Robinson, A. R., Wang, J., Gregg, S. Q., Clauson, C. L., Reay, D. P., Nasto, L. A., St Croix, C. M., Usas, A., Vo, N., Huard, J., Clemens, P. R., Stolz, D. B., Guttridge, D. C., Watkins, S. C., Garinis, G. A., Wang, Y., Niedernhofer, L. J., and Robbins, P. D. (2012) NF-kappaB inhibition delays DNA damage-induced senescence and aging in mice. J. Clin. Invest. 122, 2601-2612.

Mitra, D., Luo, X., Morgan, A., Wang, J., Hoang, M. P., Lo, J., Guerrero, C. R., Lennerz, J. K., Mihm, M. C., Wargo, J. A., Robinson, K. C., Devi, S. P., Vanover, J. C., D'Orazio, J. A., McMahon, M., Bosenberg, M. W., Haigis, K. M., Haber, D. A., Wang, Y., and Fisher, D. E. (2012) An ultraviolet-radiation-independent pathway to melanoma carcinogenesis in the red hair/fair skin background. Nature 491, 449-453. 
(42) Williams, E., Lowe, T. M., Savas, J., and DiRuggiero, J. (2007) Microarray analysis of the hyperthermophilic archaeon Pyrococcus furiosus exposed to gamma irradiation. Extremonhiles 11, 19-29.

(43) Dorazi, R., Gotz, D., Munro, S., Bernander, R., and White, M. F. (2007) Equal rates of repair of DNA photoproducts in transcribed and non-transcribed strands in Sulfolobus solfataricus. Mol. Microbiol. 63, 521-529.

(44) Christmann, M., and Kaina, B. (2013) Transcriptional regulation of human DNA repair genes following genotoxic stress: trigger mechanisms, inducible responses and genotoxic adaptation. Nucleic Acids Res. 41, 8403-8420.

(45) Parsons, J. L., and Dianov, G. L. (2013) Co-ordination of base excision repair and genome stability. DNA Repair (Amst) 12, 326-333.

(46) Jeong, H. G., Youn, C. K., Cho, H. J., Kim, S. H., Kim, M. H., Kim, H. B., Chang, I. Y., Lee, Y. S., Chung, M. H., and You, H. J. (2004) Metallothionein-III prevents gamma-ray-induced 8-oxoguanine accumulation in normal and hOGG1-depleted cells. J.Biol.Chem. 279, 34138-34149.

(47) Dianov, G. L., and Hubscher, U. (2013) Mammalian base excision repair: the forgotten archangel. Nucleic Acids Res. 41, 3483-3490.

(48) Gasparutto, D., Muller, E., Boiteux, S., and Cadet, J. (2009) Excision of the oxidatively formed 5-hydroxyhydantoin and 5-hydroxy-5-methylhydantoin pyrimidine lesions by Escherichia coli and Saccharomyces cerevisiae DNA N-glycosylases. Biochim.Bionhvs. Acta 1790, 16-24.

(49) Morland, I., Rolseth, V., Luna, L., Rognes, T., Bjoras, M., and Seeberg, E. (2002) Human DNA glycosylases of the bacterial Fpg/MutM superfamily: an alternative pathway for the repair of 8-oxoguanine and other oxidation products in DNA. Nucleic Acids Res. 30, 4926-4936. 
(50) Leipold, M. D., Workman, H., Muller, J. G., Burrows, C. J., and David, S. S. (2003) Recognition and removal of oxidized guanines in duplex DNA by the base excision repair enzymes hOGG1, yOGG1, and yOGG2. Biochemistry 42, 11373-11381.

(51) Chung, J. H., Suh, M. J., Park, Y. I., Tainer, J. A., and Han, Y. S. (2001) Repair activities of 8-oxoguanine DNA glycosylase from Archaeoglobus fulgidus, a hyperthermophilic archaeon. Mutat.Res. 486, 99-111.

(52) Lingaraju, G. M., Prota, A. E., and Winkler, F. K. (2009) Mutational studies of PaAGOG DNA glycosylase from the hyperthermophilic crenarchaeon Pyrobaculum aerophilum. DNA Repair (Amst) 8, 857-864.

(53) Thiviyanathan, V., Somasunderam, A., Hazra, T. K., Mitra, S., and Gorenstein, D. G. (2003) Solution structure of a DNA duplex containing 8-hydroxy-2'-deoxyguanosine opposite deoxyguanosine. J.Mol. Biol. 325, 433-442.

(54) Brooks, P. J., Wise, D. S., Berry, D. A., Kosmoski, J. V., Smerdon, M. J., Somers, R. L., Mackie, H., Spoonde, A. Y., Ackerman, E. J., Coleman, K., Tarone, R. E., and Robbins, J. H. (2000) The oxidative DNA lesion 8,5'-(S)-cyclo-2'-deoxyadenosine is repaired by the nucleotide excision repair pathway and blocks gene expression in mammalian cells. L.Biol. Chem. 275, 22355-22362.

(55) Kuraoka, I., Bender, C., Romieu, A., Cadet, J., Wood, R. D., and Lindahl, T. (2000) Removal of oxygen free-radical-induced 5',8-purine cyclodeoxynucleosides from DNA by the nucleotide excision-repair pathway in human cells. Proc.Natl.Acad.Sci. U.S.A. 97, 3832-3837.

(56) Corne, C., Fiche, J. B., Gasparutto, D., Cunin, V., Suraniti, E., Buhot, A., Fuchs, J., Calemczuk, R., Livache, T., and Favier, A. (2008) SPR imaging for label-free multiplexed analyses of DNA N-glycosylase interactions with damaged DNA duplexes. Analvst 133, 1036-1045. 
(57) Pande, P., Das, R. S., Sheppard, C., Kow, Y. W., and Basu, A. K. (2012) Repair efficiency of (5'S)-8,5'-cyclo-2'-deoxyguanosine and (5'S)-8,5'-cyclo-2'deoxyadenosine depends on the complementary base. DNARepair (Amst) 11, 926931.

(58) Shiraishi, M., Ishino, S., Yamagami, T., Egashira, Y., Kiyonari, S., and Ishino, Y. (2015) A novel endonuclease that may be responsible for damaged DNA base repair in Pyrococcus furiosus. Nucleic Acids Res. 43, 2853-2863.

(59) Gogos, A., and Clarke, N. D. (1999) Characterization of an 8-oxoguanine DNA glycosylase from Methanococcus jannaschii. J. Biol. Chem. 274, 30447-30450.

(60) Ravanat, J. L., Breton, J., Douki, T., Gasparutto, D., Grand, A., Rachidi, W., and Sauvaigo, S. (2014) Radiation-mediated formation of complex damage to DNA: a chemical aspect overview. Br.J.Radiol. 87, 20130715.

(61) Grasso, S., and Tell, G. (2014) Base excision repair in Archaea: back to the future in DNA repair. DNARepair (Amst) 21, 148-157.

(62) Corpet, F. (1988) Multiple sequence alignment with hierarchical-clustering. Nucleic Acids Res. 16, 10881-10890. 


\section{FIGURE LEGENDS}

\section{Figure 1.}

Chemical structures of the DNA lesions mentioned in this work. 8-oxo-dGuo, 5-OH-dHyd and 5-OH-5-Me-dHyd represent single oxidation products of 2'-deoxyguanosine, 2'deoxycytidine and thymidine, respectively. 5'R-cyclo-dAdo represents an example of $5^{\prime}, 8$ cyclonucleosides that are considered as a family of complex oxidative DNA damage. 8-oxodGuo and 5',8-cyclonucleosides were measured in T. gammatolerans DNA at basal levels and after irradiation. 8-oxo-dGuo, 5-OH-dHyd, 5-OH-5-Me-dHyd and 5',8-cyclonucleosides were tested as potential substrates for the T. gammatolerans enzymes, TGAM_1653 and TGAM_1277.

\section{Figure 2.}

Purification of recombinant TGAM_1277 and TGAM_1653 by FPLC affinity chromatography on His-Trap columns after expression in E. coli. TGAM_1277 (4.8 $\mu \mathrm{g})$ and TGAM_1653 $(5.1 \mu \mathrm{g})$ were resolved on a 10\% SDS-PAGE gel and stained with Instant Blue (Expedeon).

\section{Figure 3.}

Levels of 8-oxo-dGuo in T. gammatolerans. The "basal level" of 8-oxo-dGuo was determined with cells that were nor irradiated neither kept on ice. For gamma irradiation experiments performed at $2.5 \mathrm{kGy}$ or $5.0 \mathrm{kGy}$ : cells were harvested immediately after treatment $(0 \mathrm{~h})$ or after one hour of recovery in culture media (1h). Nonirradiated controls were stored on ice while the other cells were irradiated. Vertical bars: +/- SD. For each condition, five measurements were performed: two technical replicates for the first biological replicate and three technical replicates for the second biological replicate. 
* statistically significant difference, according to the Mann-Whitney test, with $\mathrm{p}<0.05$.

\section{Figure 4.}

Expression profiles of TGAM_1277 and TGAM_1653 in T. gammatolerans cells exposed to $\gamma$-rays at a dose of 2.5 and $5.0 \mathrm{kGy}$. TGAM_1277 and TGAM_1653 expression were quantified by real-time RT-PCR using RNA extracted from control cells (not irradiated: NI), cells collected immediately after irradiation (T0) and cells incubated for $1 \mathrm{~h}$ or $2 \mathrm{~h}$ post irradiation (T1; T2). TGAM_1277 and TGAM_1653 expression were calculated relative to the transcript levels of constitutively expressed genes (TGAM_0829, TGAM_01054, TGAM_1165, TGAM_1926) according to the formula: $2^{-\Delta \mathrm{Ct}}=2^{-(\text {CtgeneX - CtRefGenes) }}$. Each data point is the average of two biological replicates. The standard deviation is indicated by error bars. The TGAM_1277 and TGAM_1653 genes were expressed in all conditions tested.

\section{Figure 5.}

A. Base excision activities of Fpg, TGAM_1653 and TGAM_1277 assessed with three oxidative DNA lesions: 8-oxo-dGuo, 5-OH-dHyd and 5-OH-Me-dHyd. 22mer ODNs sequence: 5' -CAC TTC GG A T²CG TGA CTG ATC T-3' (control). In modified ODNs: G ${ }^{1}$ was replaced by 8-oxo-dGuo, and $\mathrm{T}^{2}$ by 5-OH-dHyd or 5-OH-5-Me-dHyd. 100 fmol ODNs were incubated with 2 pmol enzyme. For Fpg, the cleavage was carried out at $37^{\circ} \mathrm{C}$. For TGAM_1653 and TGAM_1277, the incubation was initiated at $37^{\circ} \mathrm{C}$ and the temperature was progressively increased to $65^{\circ} \mathrm{C}$. The different sizes of the cleavage products are explained by the positions of the damaged bases in the ODN sequences and by the enzymes presenting different excision processes. B. Base excision activities of Fpg, TGAM_1653 and TGAM_1277 on probes containing 8-oxo-dGuo. The influence of the opposite nucleoside was 
evaluated by using, for each enzyme, a set of four ODNs with $\mathrm{dC}, \mathrm{dT}$, dA or dG paired with the oxidative lesion.

\section{Figure 6.}

Excision reaction catalyzed by bifunctional glycosylases via $\beta$ or $\beta, \delta$-elimination mechanisms. Successive cleavages of $3^{\prime}$ and $5^{\prime}$ - strands on each side of the abasic site lead to deoxyribose residue excision. Numbers 1 to 6 were attributed to each reaction product to match with fragments obtained by MALDI-TOF mass spectrometry analysis (Figures 7 and 8 ). Number 2 (not represented) stands for the complementary strand.

\section{Figure 7.}

MALDI-TOF MS spectra resulting from the excision by Fpg, TGAM_1653 or TGAM_1277 of ODNs containing 8-oxo-dGuo. Ten pmol ODNs were incubated with 20 pmol enzyme. The incubation was initiated at $37^{\circ} \mathrm{C}$ and the temperature was progressively increased to $65^{\circ} \mathrm{C}$. The nature of the detected fragments (from 1 to 6) is described in Figure 6. "bis" indicates a secondary ion presenting two charges.

\section{Figure 8.}

MALDI-TOF MS spectra resulting from the excision by Fpg, Endo III, TGAM_1653 or TGAM_1277 of ODNs containing 5-OH-5-Me-dHyd. Ten pmol ODNs were incubated with 20 pmol enzyme. The incubation was initiated at $37^{\circ} \mathrm{C}$ and the temperature was progressively increased to $65^{\circ} \mathrm{C}$. The nature of the detected fragments (from 1 to 6 ) is described in Figure 6 . "bis" indicates a secondary ion presenting two charges.

\section{Figure 9.}


Sequence alignment of Pyrobaculum aerophilum 8-oxoG DNA glycosylase (Pa-AGOG), TGAM_1653 and TGAM_1277. Identical residues are in red, residues shared by two proteins are in blue. Residues playing an important role for catalytic activity or 8-oxo-dGuo recognition in Pa-AGOG (Q31, K140, K147, D172, D218 and W222) are indicated in green. The alignment was performed using the MultAlin tool ${ }^{62}$ followed by manual editing. 


\section{FIGURES}

Figure 1

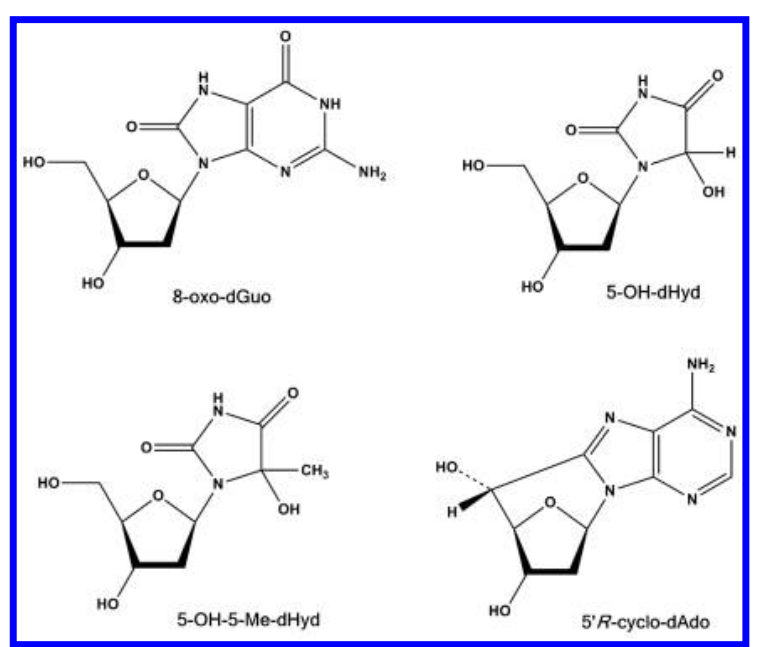

Figure 2

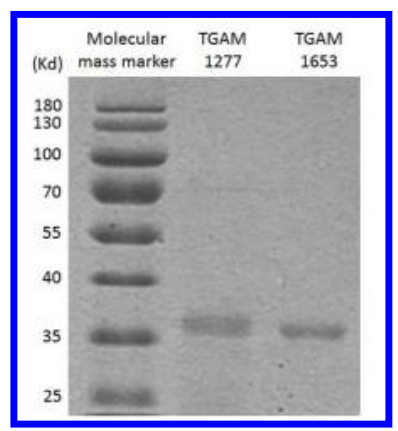


Figure 3

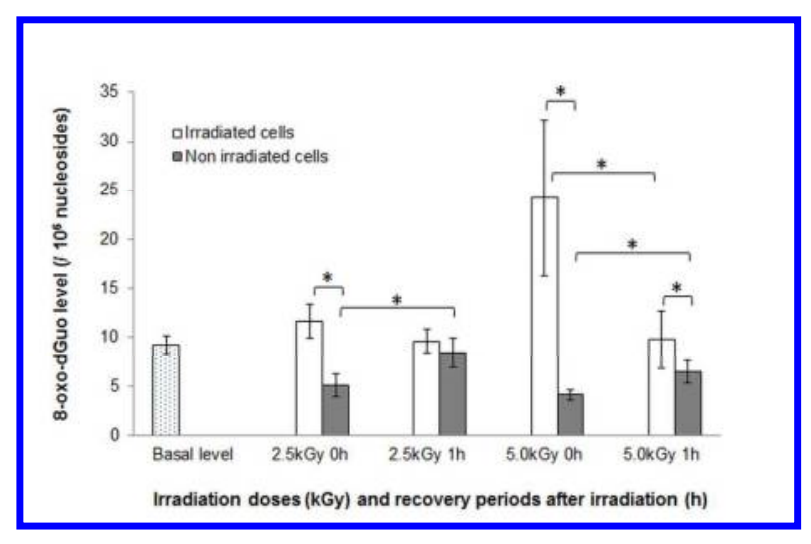

20

21

22

23

24

25

26

27

28

29

30

31

32

33

34

35

36

37

38

39

40

41

42

43

44

45

46

47

48

49

50

51

52

53

54

55

56

57

58

59

60 
Figure 4

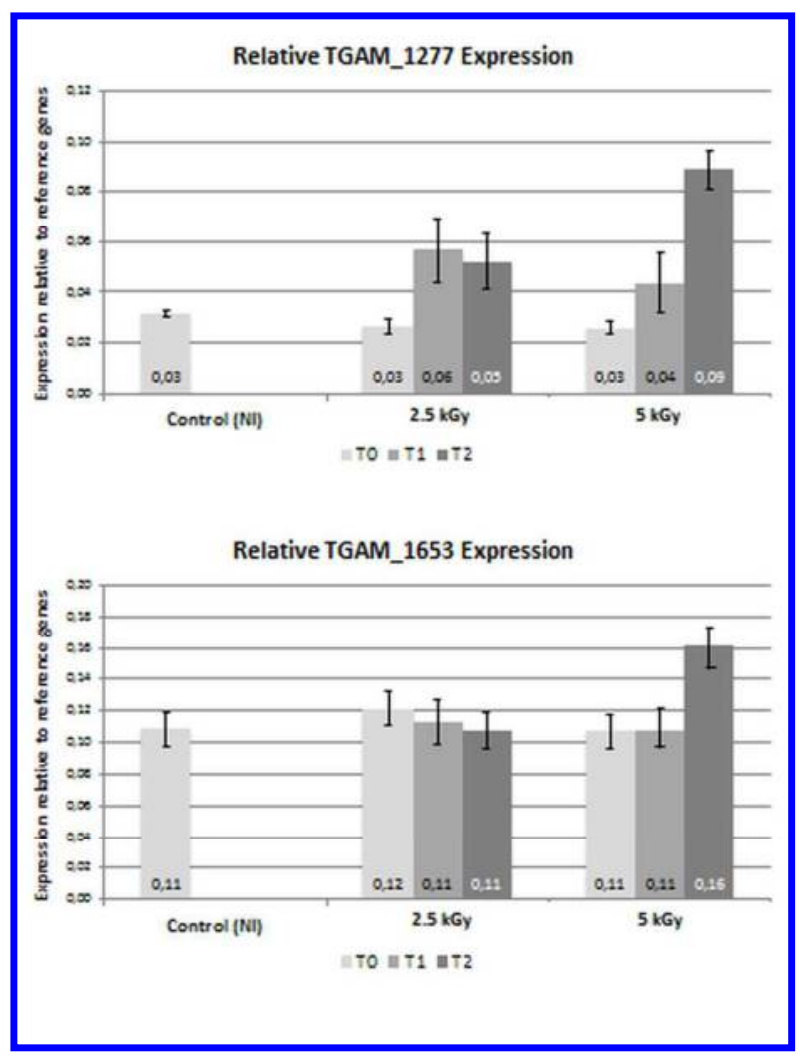

30

31

32

33

34

35

36

37

38

39

40

41

42

43

44

45

46

47

48

49

50

51

52

53

54

55

56

57

58

59

60 
Figure 5

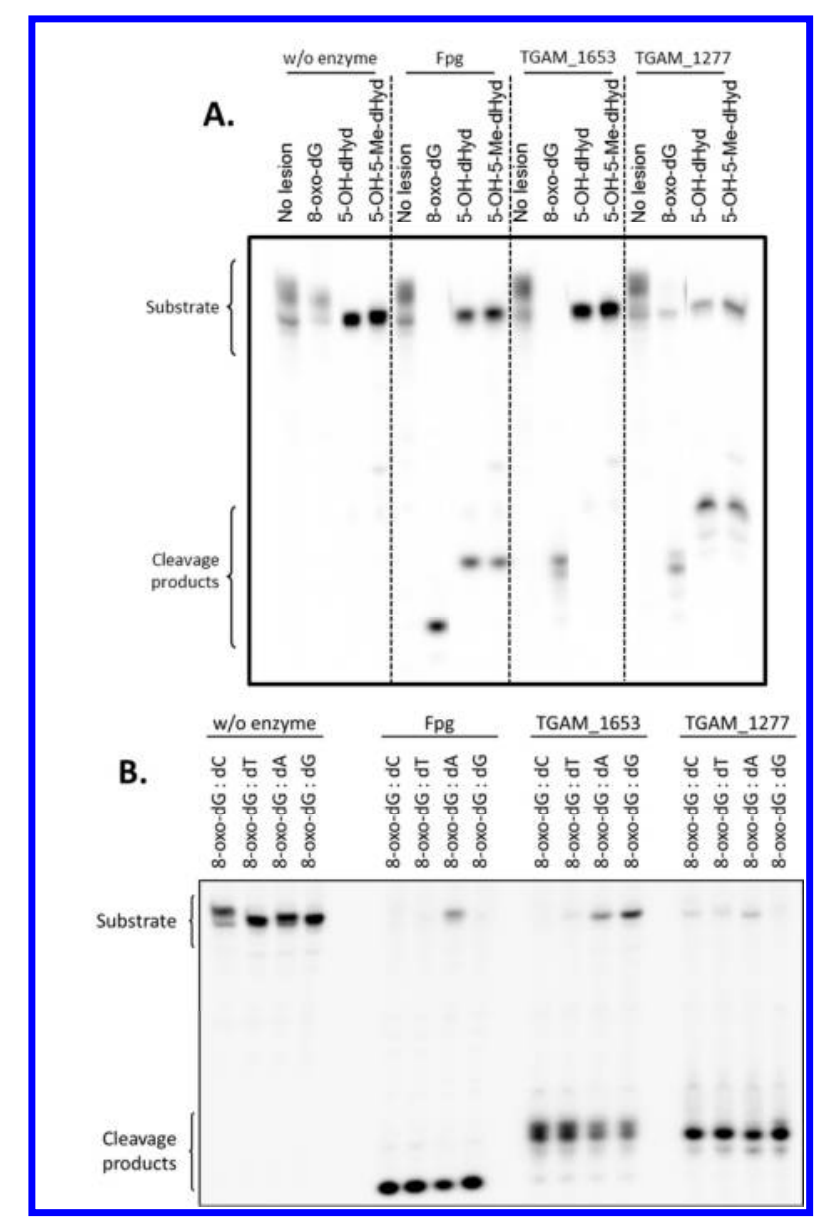

1

2

3

4

5

6

7

8

9

10

11

12

13

14

15

16

17

18

19

20

21

22

23

24

25

26

27

28

29

30

31

32

33

34

35

36

37

38

39

40

41

42

43

44

45

46

47

48

49

50

51

52

53

54

55

56

57

58

59

60 
Figure 6

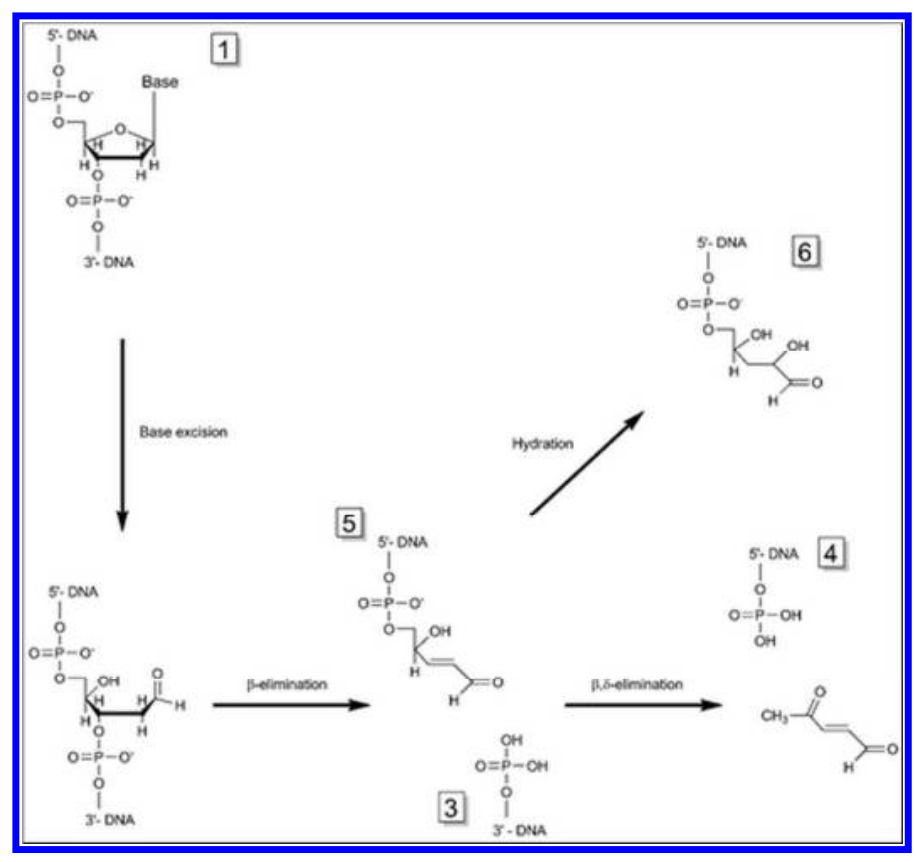


Figure 7

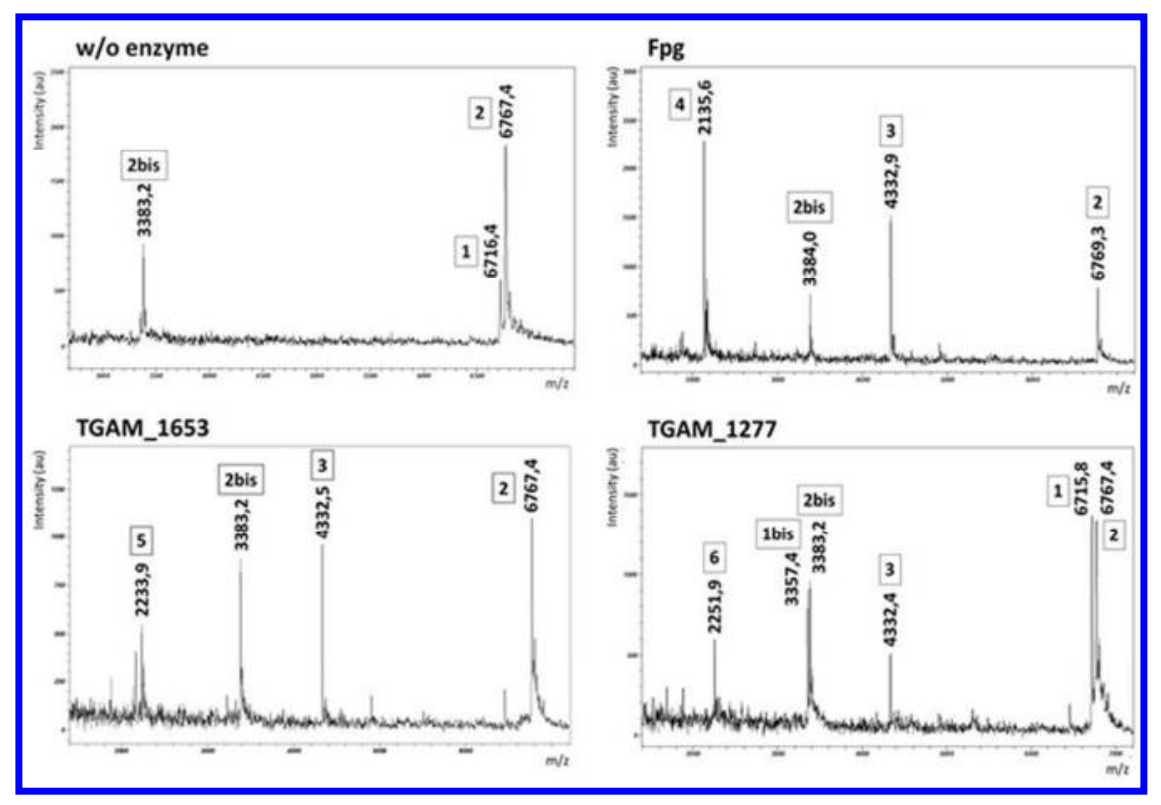

1

2

3

4

5

6

7

8

9

10

11

12

13

14
15

16

17

18

19

20

21

22

23

24

25

26

27

28

29

30

31

32

33

34

35

36

37

38

39

40

41

42

43

44

45

46

47

48

49

50

51

52

53

54

55

56

57

58

59

60 
Figure 8

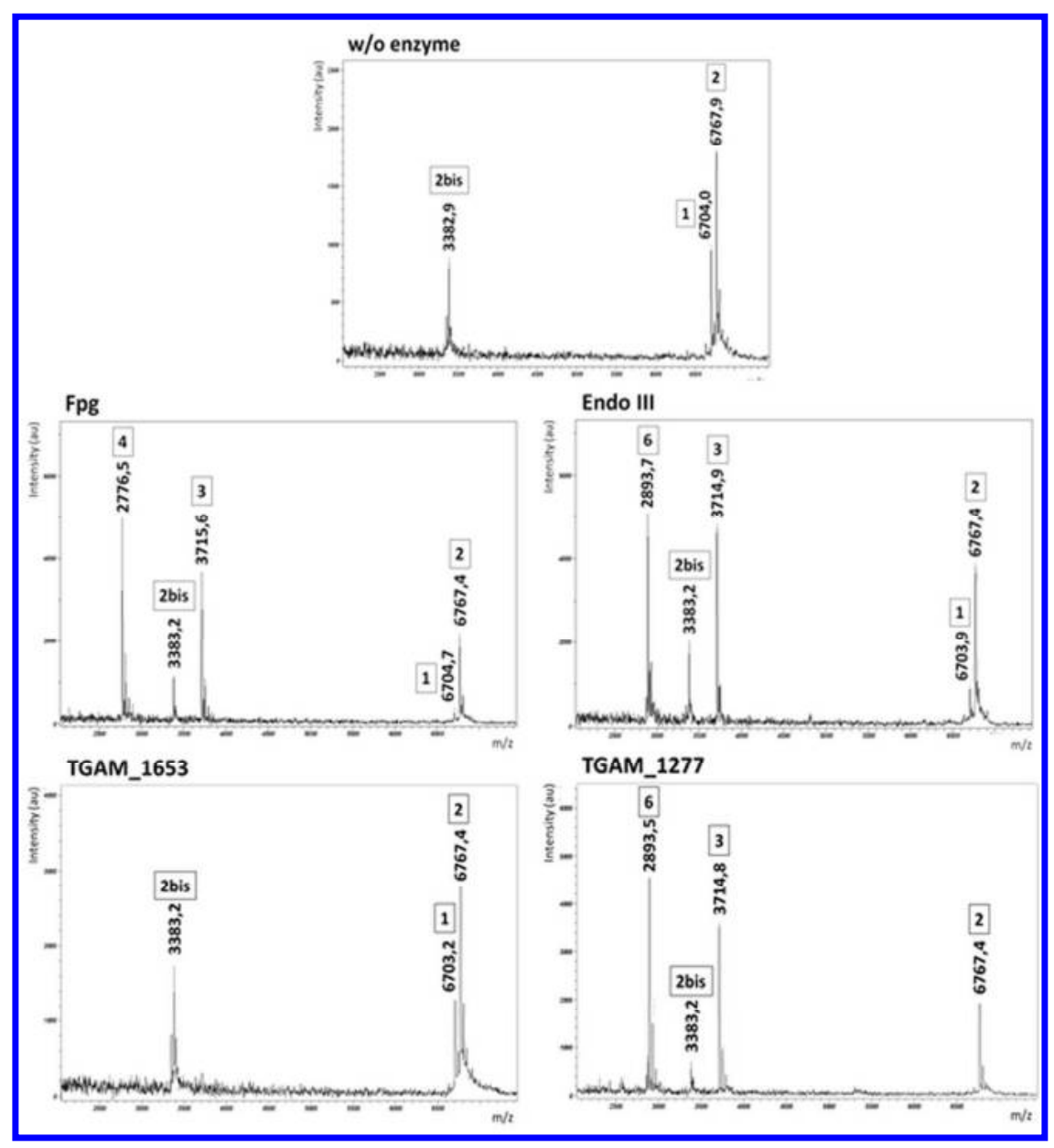


1

2

3

4

5

6

7

8

9

10

11

12

13

14

15

16

17

18

19

20

21

22

23

24

25

26

27

28

29

30

31

32

33

34

35

36

37

38

39

40

41

42

43

44

45

46

47

48

49

50

51

52

53

54

55

56

57

58

59

60

Figure 9

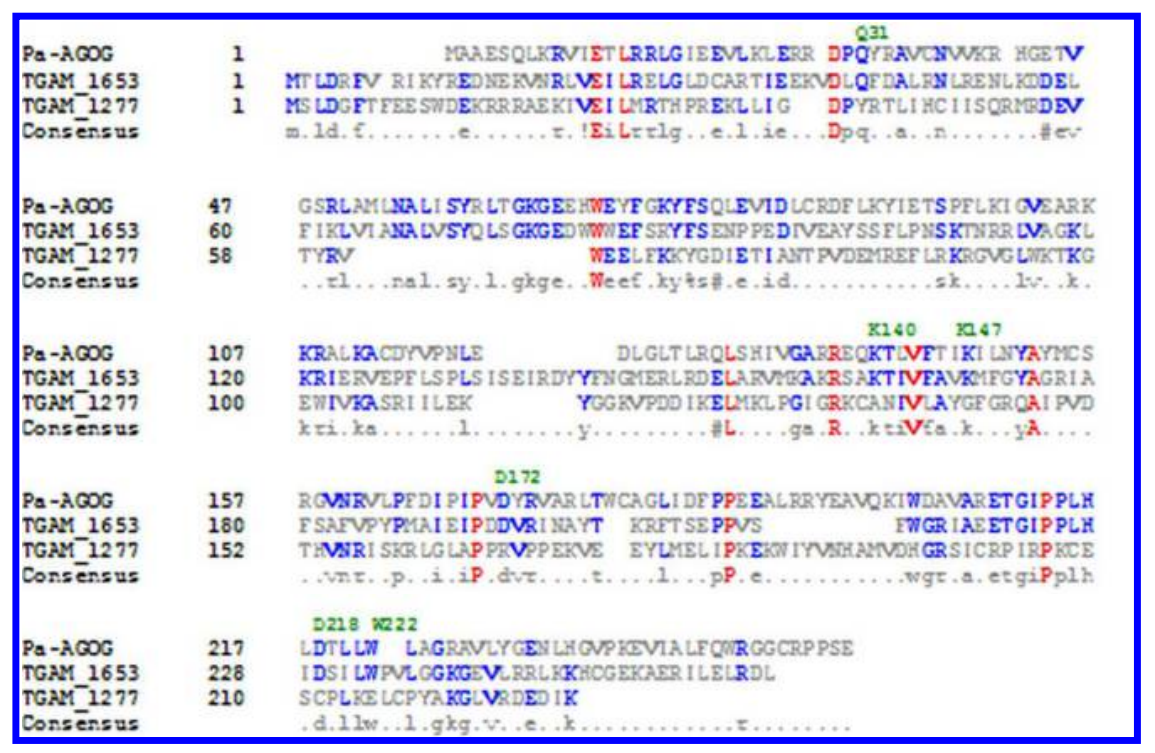

